\title{
Multiple lines of evidence reveal a new species of Krait (Squamata, Elapidae, Bungarus) from Southwestern China and Northern Myanmar
}

\author{
Ze-Ning Chen ${ }^{1,2^{*}}$, Sheng-Chao Shi ${ }^{1,3^{*}}$, Gernot Vogel ${ }^{4}$, Li Ding ${ }^{1}$, Jing-Song Shi ${ }^{5}$
}

I Chengdu Institute of Biology, Chinese Academy of Sciences, Chengdu, Sichuan 610041, China 2 Guangxi Key Laboratory of Rare and Endangered Animal Ecology, Guangxi Normal University, Guilin, Guangxi 541001, China 3 University of Chinese Academy of Sciences, Beijing 100049, China 4 Society for Southeast Asian Herpetology, Im Sand 3, Heidelberg D-69115, Germany 5 Key Laboratory of Vertebrate Evolution and Human Origins of Chinese Academy of Sciences, Institute of Vertebrate Paleontology and Paleoanthropology, Chinese Academy of Sciences, Beijing 100044, China

Corresponding authors: Li Ding (dingli@cib.ac.cn); Jing-Song Shi (shijingsong@ivpp.ac.cn)

Academic editor: R. Jadin | Received 21 December 2020 | Accepted 21 February 2021 | Published 18 March 2021

http://zoobank.org/1AB94895-532E-4998-9D63-BDD5DAC8F321

Citation: Chen Z-N, Shi S-C, Vogel G, Ding L, Shi J-S (2021) Multiple lines of evidence reveal a new species of Krait (Squamata, Elapidae, Bungarus) from Southwestern China and Northern Myanmar. ZooKeys 1025: 35-71. https://doi.org/10.3897/zookeys.1025.62305

\begin{abstract}
Kraits of the genus Bungarus Daudin 1803 are widely known venomous snakes distributed from Iran to China and Indonesia. Here, we use a combination of mitochondrial DNA sequence data and morphological data to describe a new species from Yingjiang County, Yunnan Province, China: Bungarus suzhenae sp. nov. Phylogenetically, this species forms a monophyletic lineage sister to the Bungarus candidus/multicinctus/wanghaotingi complex based on cyt $b$ and ND4 genes but forms a sister species pair with the species B. magnimaculatus Wall \& Evans, 1901 based on COI gene fragments. Morphologically, B. suzhenae sp. nov. is similar to the $B$. candidus/multicinctus/wanghaotingi complex but differs from these taxa by a combination of dental morphology, squamation, coloration pattern, as well as hemipenial morphology. A detailed description of the cranial osteology of the new species is given based on micro-CT tomography images. We revised the morphological characters of $B$. candidus/multicinctus/wanghaotingi complex and verified the validity of three species in this complex. The distribution of these species was revised; the records of $B$. candidus in China should be attributed to $B$. wanghaotingi. We also provide an updated key to species of Bungarus.
\end{abstract}

\footnotetext{
* Contributed equally as the first authors.
}

Copyright Ze-Ning Chen et al. This is an open access article distributed under the terms of the Creative Commons Attribution License (CC BY 4.0), which permits unrestricted use, distribution, and reproduction in any medium, provided the original author and source are credited. 


\section{Keywords}

Bungarus suzhenae sp. nov., cranial osteology, hemipenial morphology, micro-computed tomography, phylogeny, taxonomy

\section{Introduction}

Sound taxonomy of lethal snakes provides an essential foundation for venom research, antivenin development and proper snakebite treatment (Fry et al. 2003; Williams et al. 2011). Bungarus Daudin 1803 (commonly referred to as 'Kraits') is one of the most medically significant groups of elapid snakes in Asia, and is widely distributed from Iran and Pakistan, eastwards to China and Indonesia (Slowinski 1994; Kuch et al. 2005; Abtin et al. 2014; Ahsan and Rahman 2017; Uetz et al. 2020). Within the fourteen species currently described, Bungarus with black-and-white crossbands have been the most taxonomically problematic members of the genus and are difficult to identify in the field due to overlapping characteristics in morphology (Wall 1907; Slowinski 1994; Kuch 2007; Abtin et al. 2014). Most of these black-and-white Bungarus species are traditionally identified by the number of the dorsal crossbands on the body and tail (Slowinski 1994; Leviton et al. 2003; Zhao 2006). However, both characters within these species overlap (see: Table 1) and may lead to misidentifications.

Five taxa of Bungarus are reported from China, including B. fasciatus (Schneider, 1801), B. bungaroides (Cantor, 1839), B. multicinctus multicinctus Blyth, 1860, B. m. wanghaotingi Pope, 1928 and B. candidus (Linnaeus, 1758) (Pope 1928; Zhao and Yang 1997; Rao and Zhao 2004; Zhao 2006; Kuch 2007; Yang and Rao 2008; Xie et al. 2018). The former two species B. fasciatus and B. bungaroides are easily distinguished from their congeners by having divided subcaudal scales, as well as their unique coloration patterns (Kuch et al. 2005; Zhao 2006; Kuch 2007; Yang and Rao 2008). However, B. m. multicinctus, B. m. wanghaotingi and B. candidus are relatively difficult to identify and are differentiated from each other by the number of the white crossbands on the body and the number of ventral scales (Pope 1928; Slowinski 1994; Leviton et al. 2003; Rao and Zhao 2004; Zhao 2006). Leviton et al. (2003) proposed to raise $B$. m. wanghaotingi to species level based on lesser light crossbands on body and tail and geographically distant from B. m. multicinctus. However, Kuch (2007) considered B. candidus and B. multicinctus (including B. m. multicinctus and $B$. $m$. wanghaotingi) as a species complex based on mtDNA sequence data and similar morphology. Considering paraphyly of this complex shown in Kuch (2007), we use the term B. candidus/multicinctus/wanghaotingi complex. In addition, Kuch (2007) tentatively identified a specimen CAS 221526 from northern Myanmar as Bungarus cf. multicinctus, which is phylogenetically closer to B. niger Wall, 1908 than to all other specimens of B. multicinctus from China and Vietnam (fig. 20 in Kuch 2007). Since Kuch's (2007) unpublished dissertation, authors have used the species and subspecies categories interchangeably to describe the three names in the 
B. candidus/multicinctus/wanghaotingi complex, and the boundaries between species in this group are still subject to controversy (Nguyen et al. 2017; Xie et al. 2018).

During herpetological surveys in Yunnan Province, China, between 2016 and 2019, a series of Bungarus specimens were collected from Yingjiang County. These specimens resembled members of the $B$. candidus/multicinctus/wanghaotingi complex based on morphology, but nested phylogenetically in the same lineage as the specimen CAS 221526 reported by Kuch (2007). Based on multiple evidence including phylogenetical analysis based on three mitochondrial genes, micro-CT scanning, hemipenial morphology, and other morphological data, we evaluated the taxonomic status of these specimens and compared them to all members of the B. candidus/multicinctus/wanghaotingi complex. The results showed that the specimens from Yingjiang County can be distinguished from these taxa, along with all other congeners. We therefore describe these specimens, along with the CAS 221526 specimen from Myanmar, as a new species in this paper.

\section{Materials and methods}

\section{Sampling}

Four individuals of the Bungarus were collected from Yingjiang, western Yunnan Province, China. Before preservation, we euthanized these specimens and fixed them in $80 \%$ ethanol and then deposited in the Herpetology Museum of Chengdu Institute of Biology, Chinese Academy of Sciences, Chengdu City, Sichuan Province, China (CIB). For comparisons of taxa in B. candidus/multicinctus/wanghatingi complex, fourteen specimens of $B$. $m$. wanghaotingi were collected from southern and eastern Yunnan Province and southwestern Guangxi Province, China. Two specimens collected from Saigon, Vietnam, two specimens of $B$. m. multicinctus from Fujian Province and Zhejiang Province were also collected. Additional specimens of the $B$. candidus/multicinctus/wanghaotingi complex were examined in museum collections for morphological comparisons. A full list of specimens examined can be found in Appendix I. Comparative morphological information on other species was obtained from examined specimens and the literature sources listed in Table 1. Museum acronyms follow Leviton et al. (1985) except for collections that are not included in their list. Chengdu Institute of Biology (CIB), Shenyang Normal University (SYNU), Naturhistorisches Museum Wien, Vienna, Austria (NMW), Muséum National d'Histoire Naturelle, Paris, France (MNHN), Rijksmuseum van Natuurlijke Historie, Leiden, the Netherlands (RMNH).

To ensure the taxonomic relationships within the $B$. candidus/multicinctus/wanghaotingi complex, we included specimens of $B$. m. multicinctus near type locality, $B$. $m$. wanghaotingi near type locality, and monophyletic specimens of $B$. candidus in multiple localities from West Java, Indonesia to Binh Phuoc, Vietnam. Muscle or liver tissues were extracted from specimens before specimens were fixed, preserved in $95 \%$ ethanol, and stored at $-20{ }^{\circ} \mathrm{C}$. 


\begin{tabular}{|c|c|c|c|c|c|c|c|c|c|c|c|c|c|c|c|c|}
\hline & 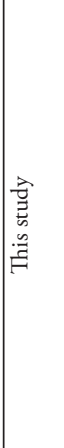 & 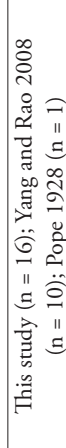 & 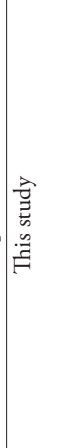 & 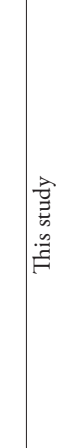 & 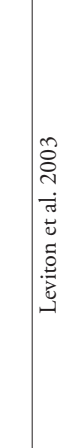 & 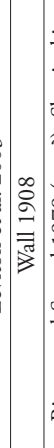 & 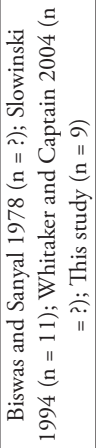 & 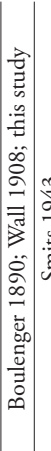 & 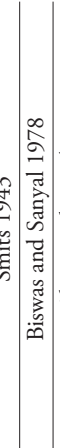 & & 㝴 & 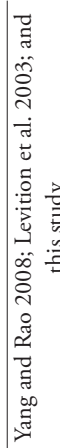 & 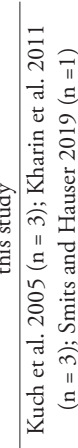 & 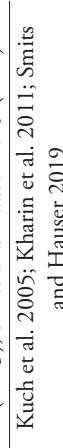 & 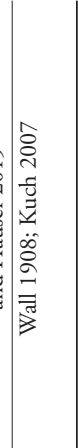 & 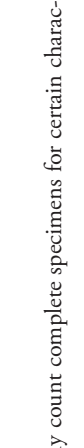 \\
\hline 0 & 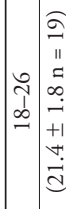 & 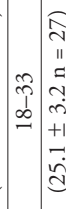 & a & 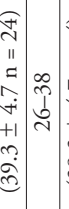 & 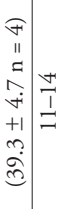 & & $\begin{array}{l}\text { ñ } \\
1 \\
\hat{\imath}\end{array}$ & 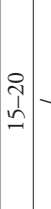 & $-\mid \begin{array}{l}\hat{f} \\
\hat{m}\end{array}$ & & & $\begin{array}{l}\hat{\tilde{T}} \\
\stackrel{-}{2}\end{array}$ & $\begin{array}{l}\tilde{N} \\
\hat{N} \\
\hat{N}\end{array}$ & $\begin{array}{l}0 \\
0 \\
b \\
0 \\
+1\end{array}$ & - & \\
\hline & 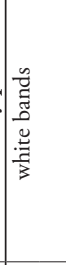 & 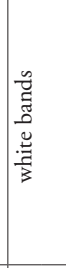 & 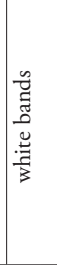 & 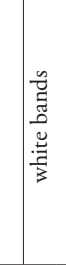 & 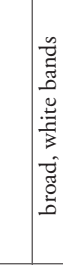 & 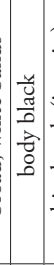 & 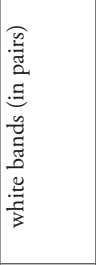 & 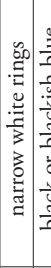 & 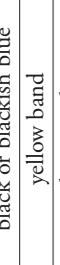 & 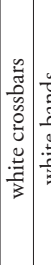 & 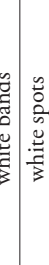 & 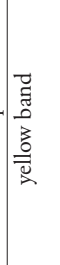 & 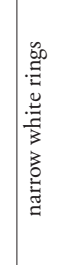 & 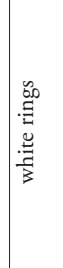 & 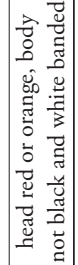 & 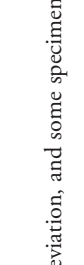 \\
\hline ฐ్ & 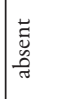 & 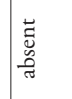 & 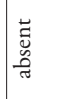 & 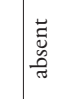 & 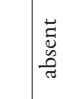 & 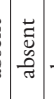 & 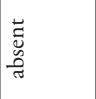 & & 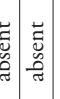 & 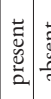 & 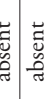 & 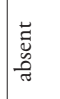 & 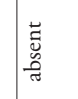 & 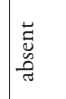 & 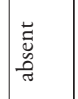 & \\
\hline$\dot{\omega}$ & 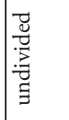 & 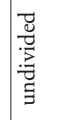 & 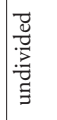 & 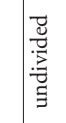 & 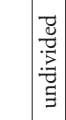 & 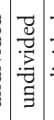 & 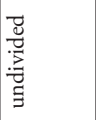 & 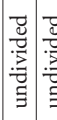 & 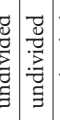 & 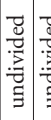 & 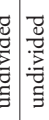 & 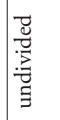 & $\frac{\bar{v}}{\bar{z}}$ & $\frac{\vec{y}}{\partial}$ & 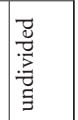 & \\
\hline 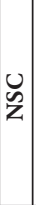 & 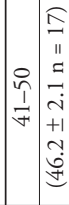 & 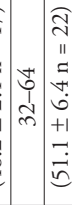 & 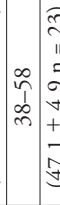 & 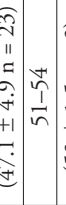 & 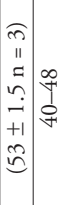 & $\mid \begin{array}{c}\hat{n} \\
\hat{1} \\
\forall\end{array}$ & 蓶 & 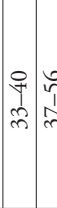 & 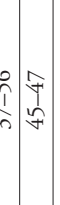 & & 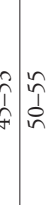 & $\vec{m}$ & $\begin{array}{l}\vec{f} \\
m \\
m\end{array}$ & $\begin{array}{l}\overrightarrow{5} \\
\dot{f}\end{array}$ & 众 & 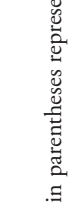 \\
\hline & 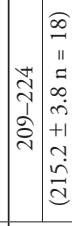 & 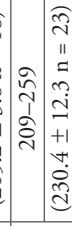 & 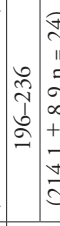 & 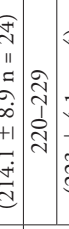 & 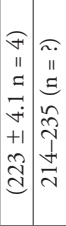 & 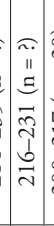 & 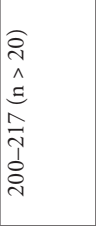 & 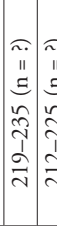 & 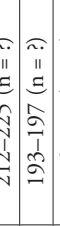 & 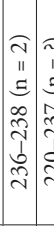 & 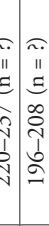 & 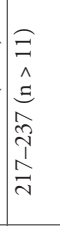 & 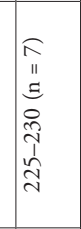 & 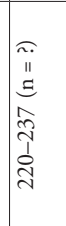 & 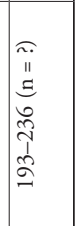 & 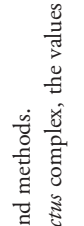 \\
\hline 它 & $\cong$ & $\cong$ & $\cong$ & $\cong$ & $\cong$ & $\cong$ & $\cong$ & $\simeq \because$ & $\theta \cong$ & $\Rightarrow=$ & $=\approx$ & $\cong$ & $\cong$ & $\cong$ & $\dddot{m}$ & \\
\hline & 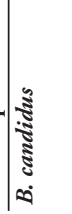 & 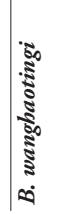 & 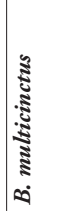 & 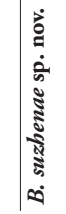 & 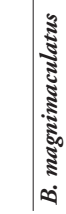 & $\mid$ & ڤ્ & 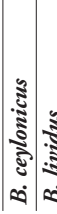 & 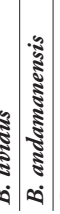 & 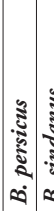 & 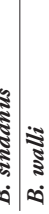 & 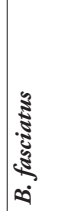 & 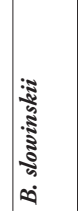 & 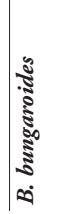 & 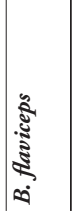 & 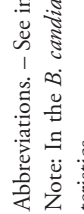 \\
\hline
\end{tabular}




\section{Molecular phylogenetic analysis}

Genomic DNA was extracted from muscle or liver tissues using QIAamp DNA Mini Kit (QIAGEN, Hilden, Germany). We sequenced three mitochondrial genes: cytochrome $b$ (cyt b) (Burbrink et al. 2000), NADH dehydrogenase subunit 4 (ND4) (Arevalo et al. 1994) and cytochrome $C$ oxidase 1 (COI) (Che et al. 2012). PCR amplifications were

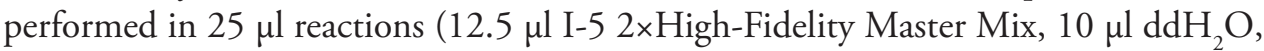
$1 \mu \mathrm{l} \mathrm{F}$-primers, $1 \mu \mathrm{l}$ R-primers, $0.5 \mu \mathrm{l}$ DNA template) under the following cycling conditions: initial denaturation for 2 min at $95^{\circ} \mathrm{C}, 35$ cycles with denaturation at $94^{\circ} \mathrm{C}$ for $40 \mathrm{~s}$, annealing at different temperatures $\left(48.5^{\circ} \mathrm{C}\right.$ for cyt $b$ and COI, $56^{\circ} \mathrm{C}$ for ND4) for $25 \mathrm{~s}$, extension at $72^{\circ} \mathrm{C}$ for $15 \mathrm{~s}$, and final extension for 2 min at $72{ }^{\circ} \mathrm{C}$. PCR products were sequenced by Beijing Qingke New Industry Biotechnology Co., Ltd. Raw trace files for sequences were edited in Geneious 7 (Biomatters Limited, New Zealand) before constructing alignments using MEGA 7 (Kumar et al. 2016). Due to differences in taxon sampling for each gene, we reconstructed separate alignments for phylogenetic analysis. The first was based on a concatenated sequence alignment using cyt $b$ and ND4, while the other was based solely on COI. Sequences were uploaded to GenBank under the following accession numbers: MN165132-MN165173. Comparative sequences of available species were downloaded from GenBank (Suppl. material 1: Table S1). Distribution of sequences localities were present in Fig. 1.

Optimal models of sequence evolution of nucleotide substitution were identified by BIC using Partition finder 2.1.1 (Lanfear et al. 2012). We performed maximum likelihood (ML) analysis using RaxML v8 (Stamatakis et al. 2014) and IQ-TREE (Nguyen, et al. 2015) respectively. The first ML analysis was implemented in RaxML v8 (Stamatakis et al. 2014) following GTRGAMMA model with 1000 fast bootstrap replicates to assess node support. We consider bootstrap proportions of $70 \%$ or greater as strong support for existence of a clade following Hillis and Bull (1993). The second ML analysis was implemented in IQ-TREE (Nguyen et al. 2015), with Ultrafast Bootstrap Approximation (UFB; Hoang et al. 2017) using 5000 bootstrap replicates to assess node support. Nodes with UFB values of 95 and above were considered significantly supported (Hoang et al. 2017). The best evolution models were shown in supplementary materials (Suppl. material 1: Table S2). Bayesian inference phylogenetic trees were inferred using MrBayes 3.2 (Ronquist et al. 2012). We used a random starting tree and four independent runs with a maximum of 20 million generations each, sampled every 1000. Runs were stopped when the average standard deviation of split frequencies had reached 0.001 . The first $25 \%$ of each run were discarded as burn-in. Nodes with Bayesian posterior probabilities (BPP) of 0.95 and above were considered well supported (Huelsenbeck et al. 2001).

\section{Morphological analysis}

Measurements of head and head scales were taken with a digital caliper and rounded to the nearest $0.1 \mathrm{~mm}$; snout-vent length and tail length were taken with a measuring tape and rounded to the nearest $1 \mathrm{~mm}$. Terminology and descriptions follow Slowinski 


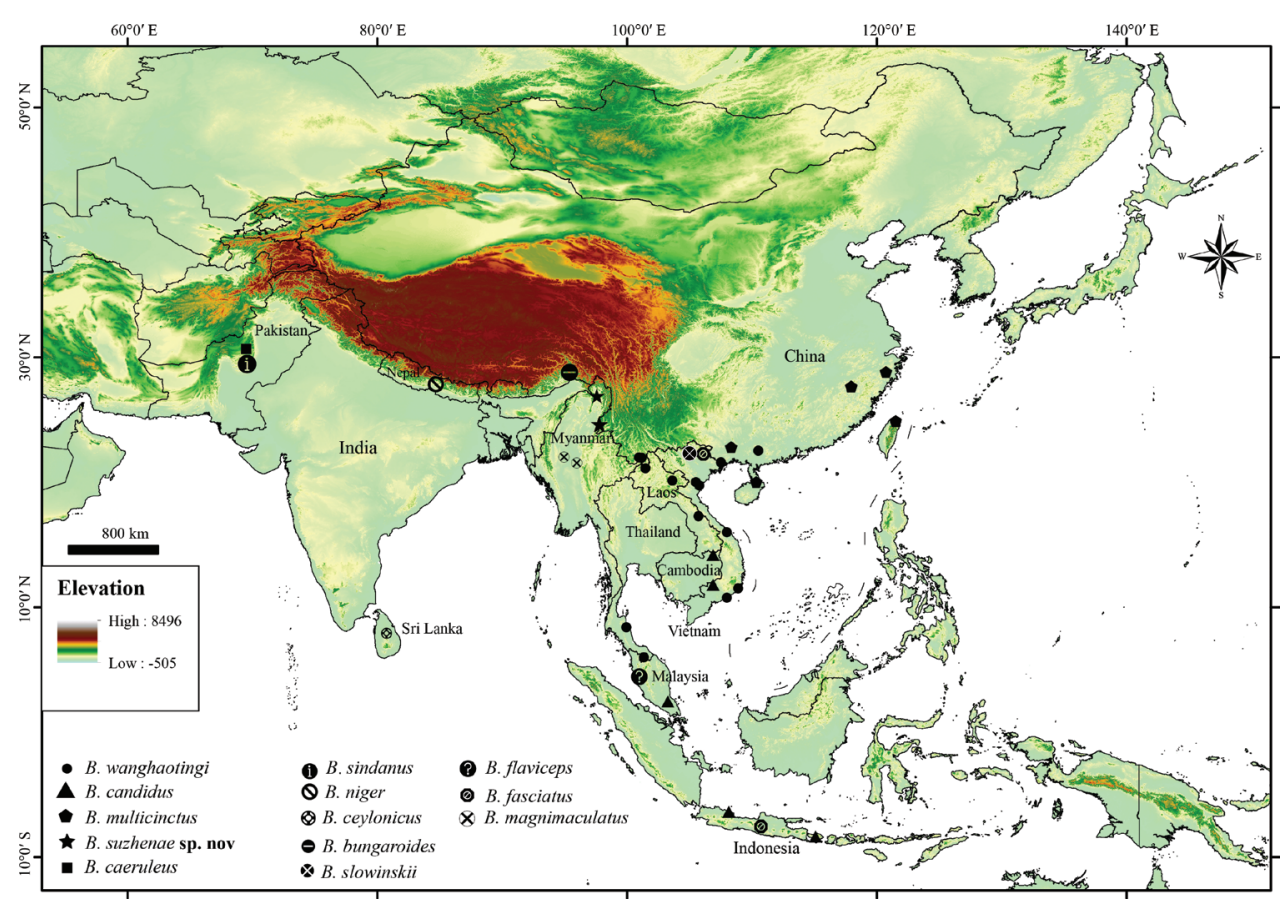

Figure I. Distribution map of molecular samples localities of Bungarus in this study.

(1994), Vogel et al. (2004), and Kuch et al. (2005). Morphometric and meristic characters are abbreviated as follows: total length (TL), from the tip of snout to the tip of tail; snout-vent length (SVL), from the tip of snout to anterior margin of cloaca; tail length (TaL), from posterior margin of cloaca to the tip of tail; ratio of tail length to total length (TaL/TL); head length (HL), from the snout tip to the posterior margin of the mandible; head width (HW) was measured at the widest part of the head on posterior side; head height $(\mathrm{HH})$, at the maximal highest part of the head; the eye horizontal diameter (ED); the eye vertical diameter (VED); distance lower eye margin-edge of the lip (DEL) was measured from the ventral margin of the middle of the eye to the ventral margin of the upper labial below it; the distance from the eye to the nostril (DEN) was measured from the anterior margin of the eye to the posterior margin of the nostril; the dorsal scale rows (DSR) were counted at one head length behind the head, at midbody, and at one head length before the vent; ventral scales (VEN) were counted according to Dowling (1951); half ventrals were counted as one. The enlarged shield(s) anterior to the first ventral were regarded as preventral(s); for subcaudals (SC), first scale under the tail meeting its opposite was regarded as the first subcaudal scale, and the unpaired terminal scute was not included in the number of subcaudals; paired scales on head were counted on both sides of the head and presented in left/right order; supralabials (SL); infralabials (IL) were considered scales and shields that are completely below a supralabial and border the gap between lips. For the number of white bands on the body (BB) and white bands on the tail (TB), incomplete white rings were counted as one. Sex was determined by making a small incision below the vent 
to visually inspect for the existence of hemipenes. Descriptions of the hemipenes were based on one population of the new species and three populations of the $B$. candidus/ multicinctus/wanghaotingi complex. Hemipenis terminology follows Dowling (1951) and the organs were prepared based on Jiang (2010).

For obtaining information on skeletal morphology, micro-CT scans of skulls were carried out using a 225-kV micro-computerized tomography, developed by the Institute of High Energy Physics (IHEP), Chinese Academy of Sciences (CAS). A total of 720 transmission images were reconstructed into a $2048 \times 2048$ matrix of 1536 slices using two-dimensional reconstruction software developed by IHEP, CAS. The final CT reconstructed skull images were exported with a minimum resolution of 14.1 (Holotype) and 29.0 (paratype) $\mu \mathrm{m}$. The dataset of the $3 \mathrm{D}$ models included in this study has been uploaded to the online publicly accessible repository ADMorph at http://www.admorph.org/ (Hou et al. 2020).

\section{Results}

\section{Phylogenetic analysis}

The concatenated alignment for cyt $b$ and ND4 was 1934 bp in length $(1069+865 \mathrm{bp}$, respectively) and contained a total of twelve Bungarus species. The COI alignment was $613 \mathrm{bp}$ and contained a total of five taxa. Our results show that the most well-supported cyt $b$-ND 4 and COI phylogenetic trees were achieved by using Bayesian Inference (BI), followed by Maximum likelihood RaxML (ML) and IQ-TREE (UFB), respectively.

The topological structures of the combined cyt $b$ and ND4 sequences (Fig. 2) concur with an earlier study by Kuch (2007). The new species forms a monophyletic lineage with strong support (BI 1.00/ML 100/UFB 100) sister to the B. candidus/multicinctus/ wanghaotingi complex. Within the complex, three strongly supported (BI 0.92/ML 87/ UFB 88) monophyletic lineages are identified. The first is $B$. wanghaotingi including specimens from localities near type locality and other specimens from Southern China, Southwestern China, Vietnam, Laos and Southern Thailand; the second is B. candidus, including specimens from Java and Bali Island, Peninsular Malaysia; the third is $B$. multicinctus, including specimens near type locality and from other localities in Eastern and Southern China. The two lineages B. wanghaotingi and B. candidus consist of a clade sister to $B$. multicinctus. The uncorrected $p$-distances of available cyt $b$ sequences between the Bungarus species are shown in the supplementary material (Suppl. material 1: Table S3). The distances between the new species and its closest congeners in the $B$. candidus/multicinctus/wanghaotingi complex range from (9.7\%-11.6\%), similar to the distance between $B$. niger and the $B$. candidus/multicinctus/wanghaotingi complex (11.0\%-12.4\%). The genetic distances between the three lineages of the $B$. candidus/ multicinctus/wanghaotingi complex were relatively small, ranging from $1.6 \%$ to $3.3 \%$.

In the phylogenetic analyses for the COI alignment (Fig. 3), the new species forms a lineage sister to $B$. magnimaculatus instead of the $B$. candidus/multicinctus/wanghaotingi complex. The specimens of $B$. magnimaculatus from three localities of Myanmar were formed by two lineages with short branches similar to an earlier study (Nguyen et al. 


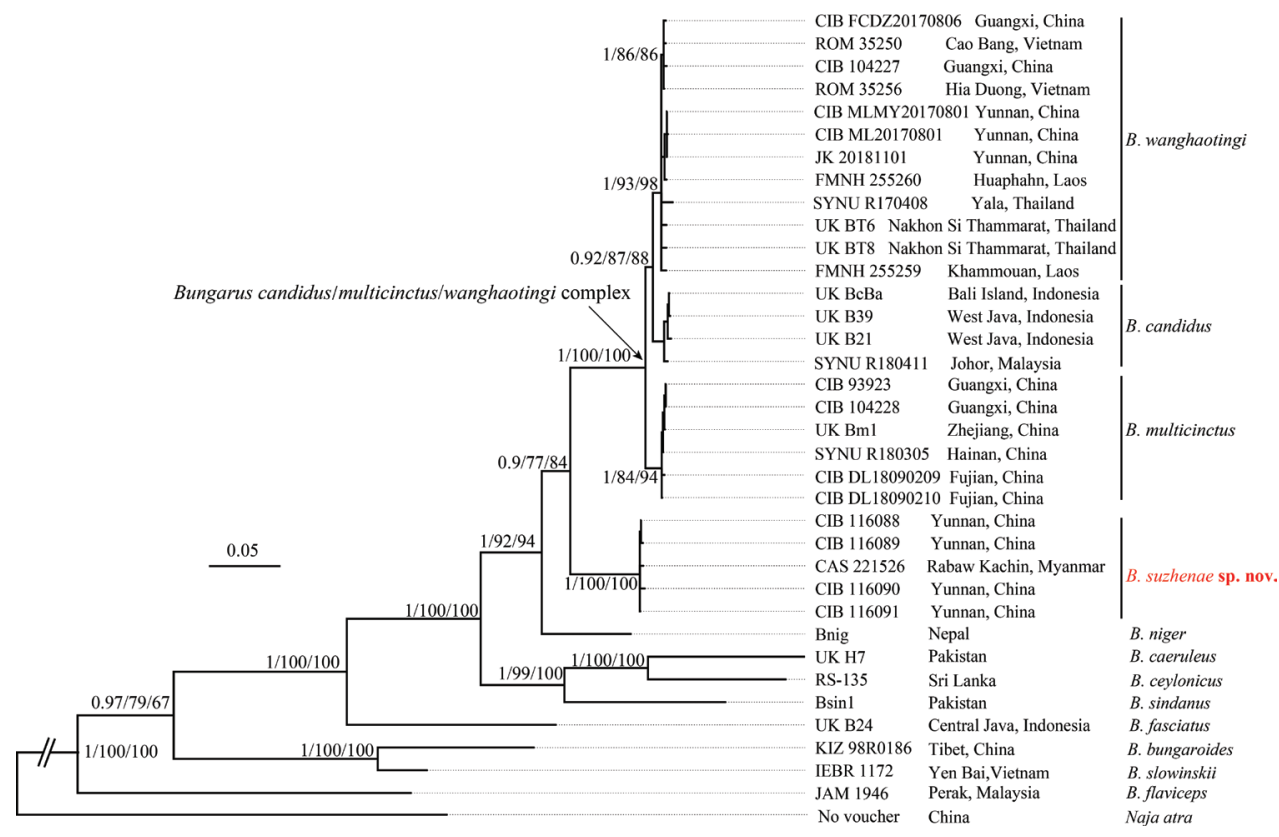

Figure 2. Bayesian inferred tree of the genus Bungarus based on combined cyt $b$ and ND4 genes fragments. The major clade genetic events BI/ML/IQ posterior probabilities, bootstrap and UFB values were presented (the ones lower than 50 are displayed as “-”).

2017). We regard the two lineages of $B$. magnimaculatus as a species complex. The distinct pairwise genetic distance between these two lineages (2.4\%-3.1\% for COI) indicates that the species diversity of this species may be underestimated. The topology of the B. candidus/multicinctus/wanghaotingi complex agrees with the concatenated cyt $b$-ND4 gene trees and can be considered to constitute three strongly supported lineages (BI 1.00/ML 95/UFB 85) with very short branch lengths. The uncorrected $p$-distances of COI between the species groups are shown in the supplementary material (Suppl. material 1: Table S4). The new species is separated from the $B$. candidus/multicinctus/wanghaotingi complex by a distinct distance of $4.4 \%-5.0 \%$, equivalent to the distance between $B$. magnimaculatus and the $B$. candidus/multicinctus/wanghaotingi complex (4.4\%-6.5\%). The high pairwise distances between the new species and its congeners support its recognition as a distinct, independently evolutionary lineage that is not conspecific with any other congeners.

\section{Morphological analysis}

Morphologically, the three taxa of $B$. candidus/multicinctus/wanghaotingi complex are different from each other in hemipenial morphology, and coloration patterns (morphology of white bands, ventral coloration, and coloration on temporal and lateral neck regions) (Tables 1, 2, Figs 4-9). Thus, we confirm these three monophyletic taxa of $B$. candidus/multicinctus/wanghaotingi complex as three distinct species: $B$. candidus (Linnaeus, 1758), B. multicinctus Blyth, 1860, and B. wanghaotingi Pope, 1928. 


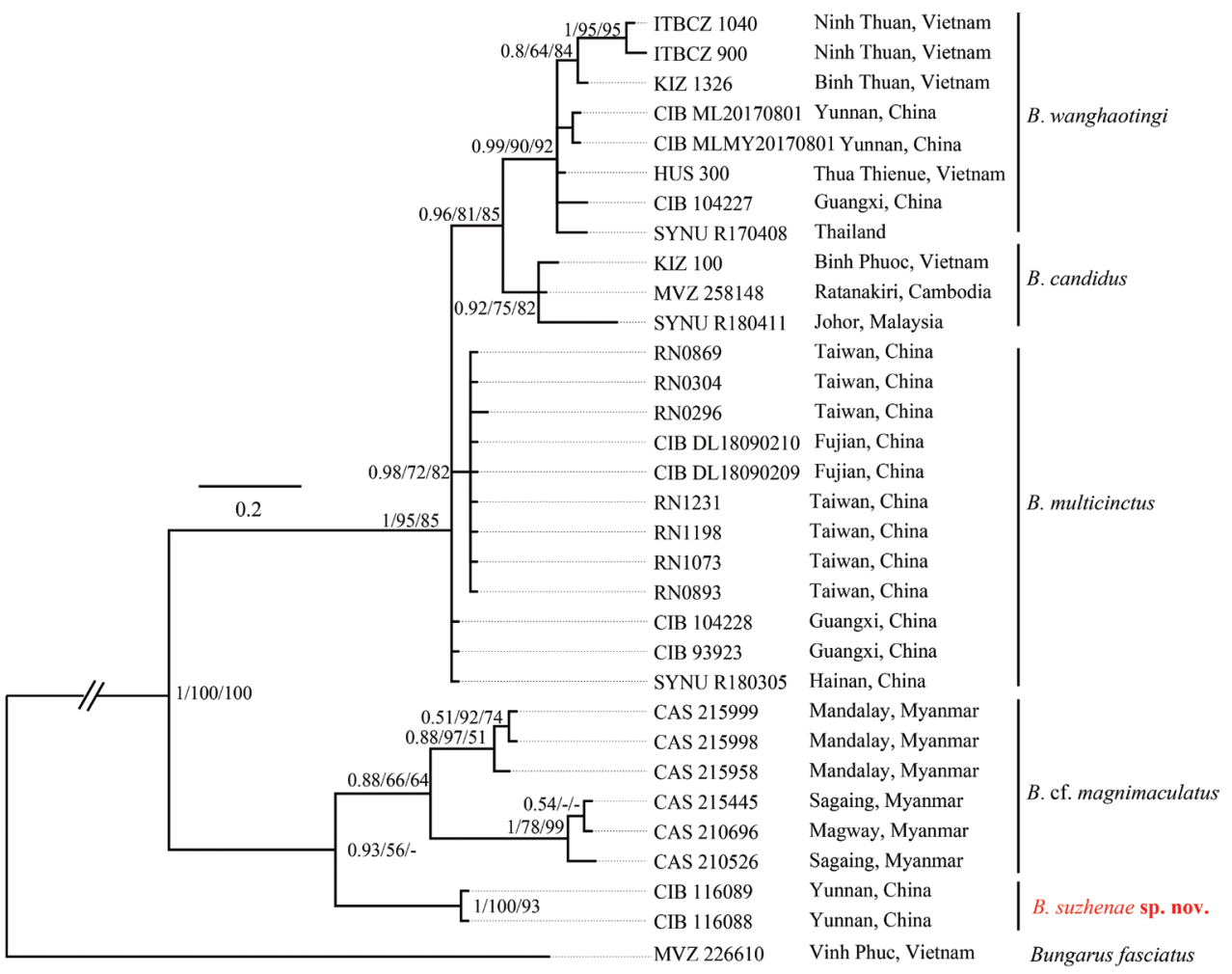

Figure 3. Bayesian inferred tree of the genus Bungarus base on COI genes fragments. The major clade genetic events BI /ML/IQ posterior probabilities, bootstrap and UFB values were presented (the ones lower than 50 are displayed as "-").

The specimens from Yingjiang (Yunnan Province) and Myanmar differ from other species of Bungarus in crossbands shape, tail pattern (Figs 4, 5, Table 2), head pattern (Fig. 6), mid-body pattern (Fig. 7), the maxilla teeth (Fig. 8 and Table 3) and hemipenial morphology (Fig. 9, Table 2). Therefore, combining morphological and molecular evidence, we identify those specimens from Yingjiang, Yunnan Province, and Myanmar as a new species.

\section{Taxonomy}

\section{Bungarus candidus/multicinctus/wanghaotingi complex}

\section{Bungarus candidus (Linnaeus, 1758)}

Figs 4C, D, 5C, D, 6C, D, 7C, D, 9D-F

[English name: Blue Krait]

[Chinese name: 马来环蛇]

Coluber candidus Linnaeus 1758: 223.

Bungarus candidus - Cantor 1847 

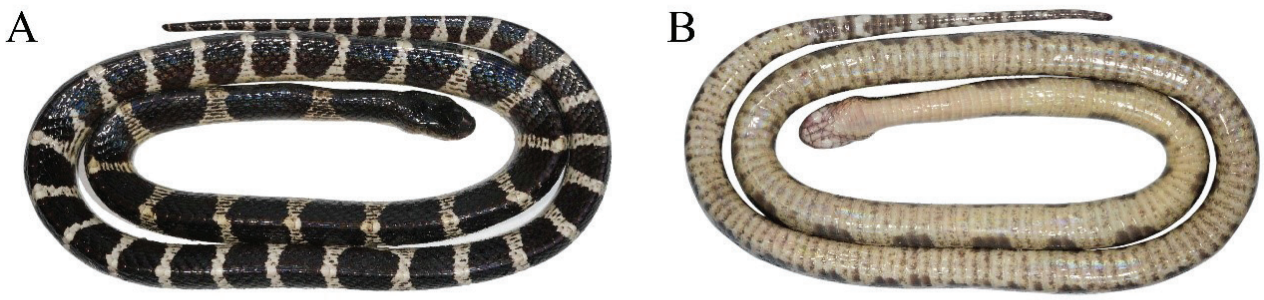

C
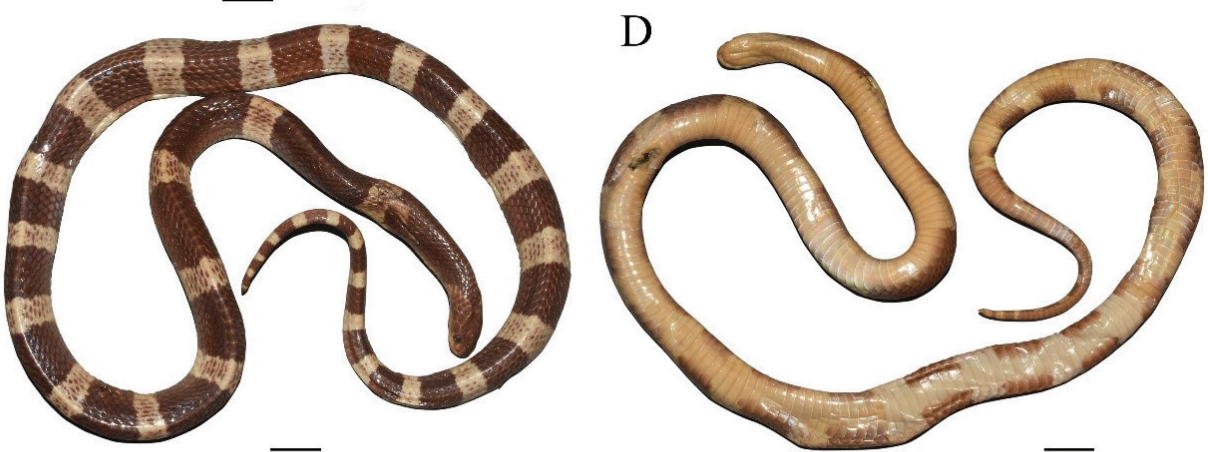

$\mathrm{E}$

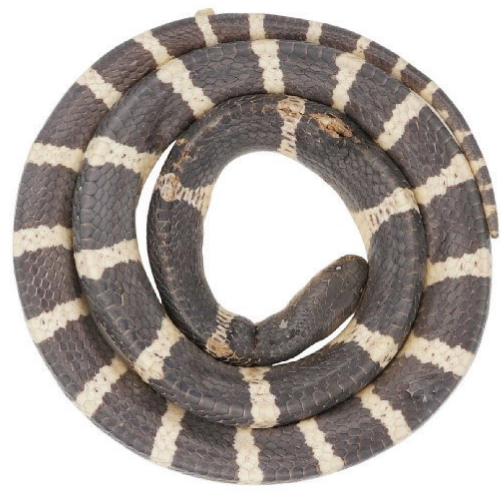

$\mathrm{F}$

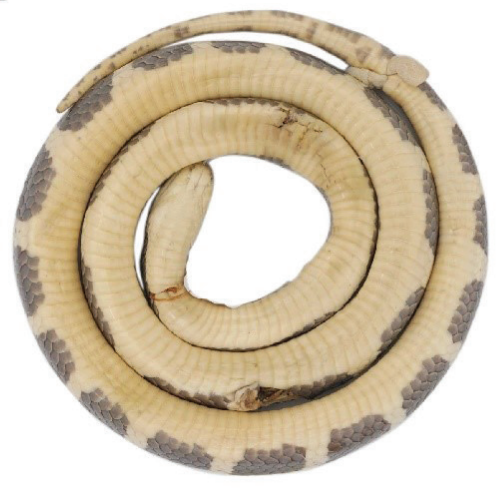

Figure 4. Dorsal (left) and ventral (right) view of adults of the Bungarus candidus/multicinctus/wanghaotingi complex A, B Bungarus multicinctus, adult male, CIB DL2019051701 from Lishui, Zhejiang, China C, D $B$. candidus, female, NMW 9486:1 from Pelambang, Java E, F B. wanghaotingi, male, CIB MLML20170801 from Mengla, Yunnan, China. Scale bars: $20 \mathrm{~mm}$.

Bungarus semifasciatus Boie 1827

Aspidoclonion semifasciatum - Wagler 1828

Bungarus candidus var. semifasciata - Werner 1900

Bungarus javanicus Kopstein 1932 (fide Slowinski 1994)

Bungarus candidus - Smith 1943: 416

Type locality. "Indiis" (in error). Holotype: NRM 37 (formerly ZIUS 89).

Typical $B$. candidus possesses following morphological characters based on the examination of 19 specimens from Sumatra and Java, Indonesia; Peninsular Malaysia 
(Appendix 1): (1) Dorsum of most specimens with $21.4 \pm 1.8,(18-26)$ broad white crossbands, with each band covers $3.8 \pm 0.6$, (3.0-5.0) vertebral scales on midbody, (Figs 4C, D, 5C, D), uniform black in some populations (Kuch 2007); (2) ventral body immaculate white, without brown pigments (Figs 4C, D, 5C, D); (3) scales on temporal area and lateral neck stained white, contrast with neighbor scales on neck in adults, creamy white in juveniles (Fig. 6C, D); (4) black bands on body large, covering 3-5 vertebral scales on middle body, intruding to white ventral body, ventrals with narrow black edges 1-2 times of outer dorsal scales (Fig. 7C, D); (5) ventral tail with broad dark crossbands (Figs 4D, 5D); (6) posterior maxilla teeth four $(n=9)$, slightly curved behind, (Table 3); (7) prefrontal suture 1.4-2.4 $(\mathrm{n}=17)$ times the length of internasals suture; (8) VEN $=209-224(\mathrm{n}=18), \mathrm{NSC}=41-50(\mathrm{n}=17)$.

The hemipenes of B. candidus is described based on photos of a male (Fig. 9D-F, collecting No. RH06153, total length $120 \mathrm{~cm}$ ) from Phong Nha-Ke Bang National Park Administration, Quang Binh Province, Vietnam, by Ralf Hendrix. This specimen was tentatively identified as $B$. candidus by the presence of $(1,2,4-8)$ characters in the former morphological description. The hemipenis was partially everted, with large spines present on the medial portion of the organ at the position of the first subcaudal scale; smaller spinous calyces present near the base and another spinous zone present posterior from the row of larger spines. Spinous calyces along organ all elongated, robust at bases and gradually tapering to a tip without distinct bordering. Tips of spines strongly keratinized, semitransparent when fresh, bent towards the base of hemipenes. Sulcus not shown in the photos.

Distribution. This species is known from following localities based on specimens examined and/or DNA sequences data: Java and Sumatra Island, Indonesia; Peninsular Malaysia; Cambodia; Central and Southern Vietnam.

\section{Bungarus multicinctus Blyth, 1860}

Figs 4A, B, 5A, B, 6A, B, 7A, B, 8E, 9A-C

[English name: Many-banded Krait]

[Chinese name: 银环蛇]

Bungarus multicinctus BLYTH 1860: 98.

Bungarus semifasciatus Günther 1858: 221 (not of Boie)

Bungarus candidus var. multicinctus - Boulenger 1896: 369

Type locality. Likely Amoy (now Xiamen, Fujian Province, China), possibly Formosa (Taiwan, China). Holotype: lost (fide Smith 1943; Nguyen et al. 2009)

This species was described based on one specimen from Amoy (Blyth 1860). The following description is based on 24 examined specimens from Southern China (Appendix 1): (1) narrow white dorsal crossbands $39.3 \pm 4.7$ (31-50), with each $1.4 \pm 0.4$ (1.0-2.0) vertebral scales long at midbody (Tables 1, 2, Figs 4A, B, 5A, B); (2) ventral body white scattered with dense brown pigment on adults $(n=19)$ (Fig. 3B), indistinct on some juveniles (Fig. 5B); (3) scales on neck and head of adults uniform black, scales 


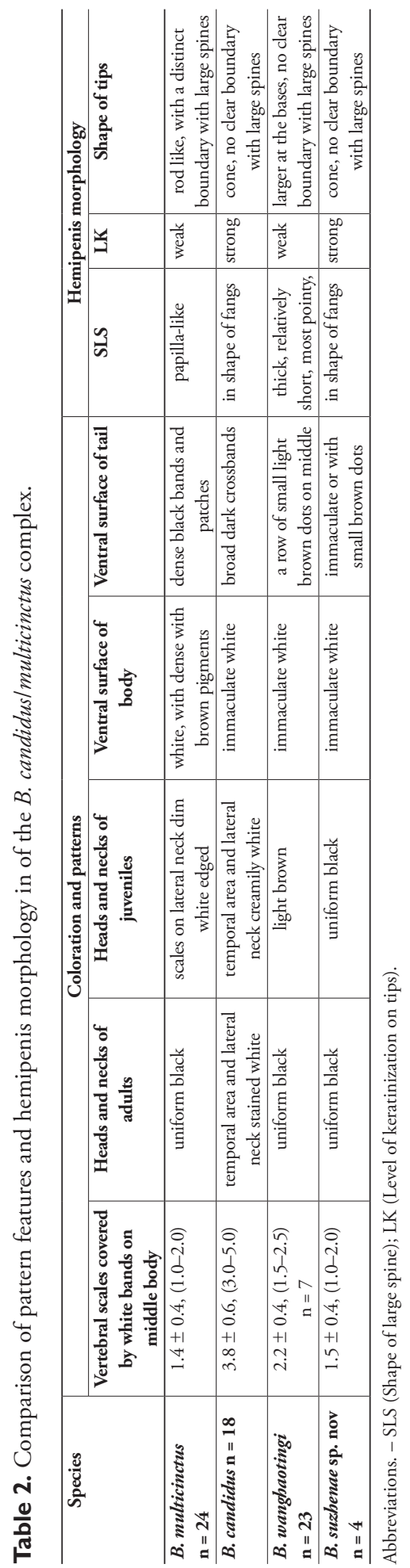



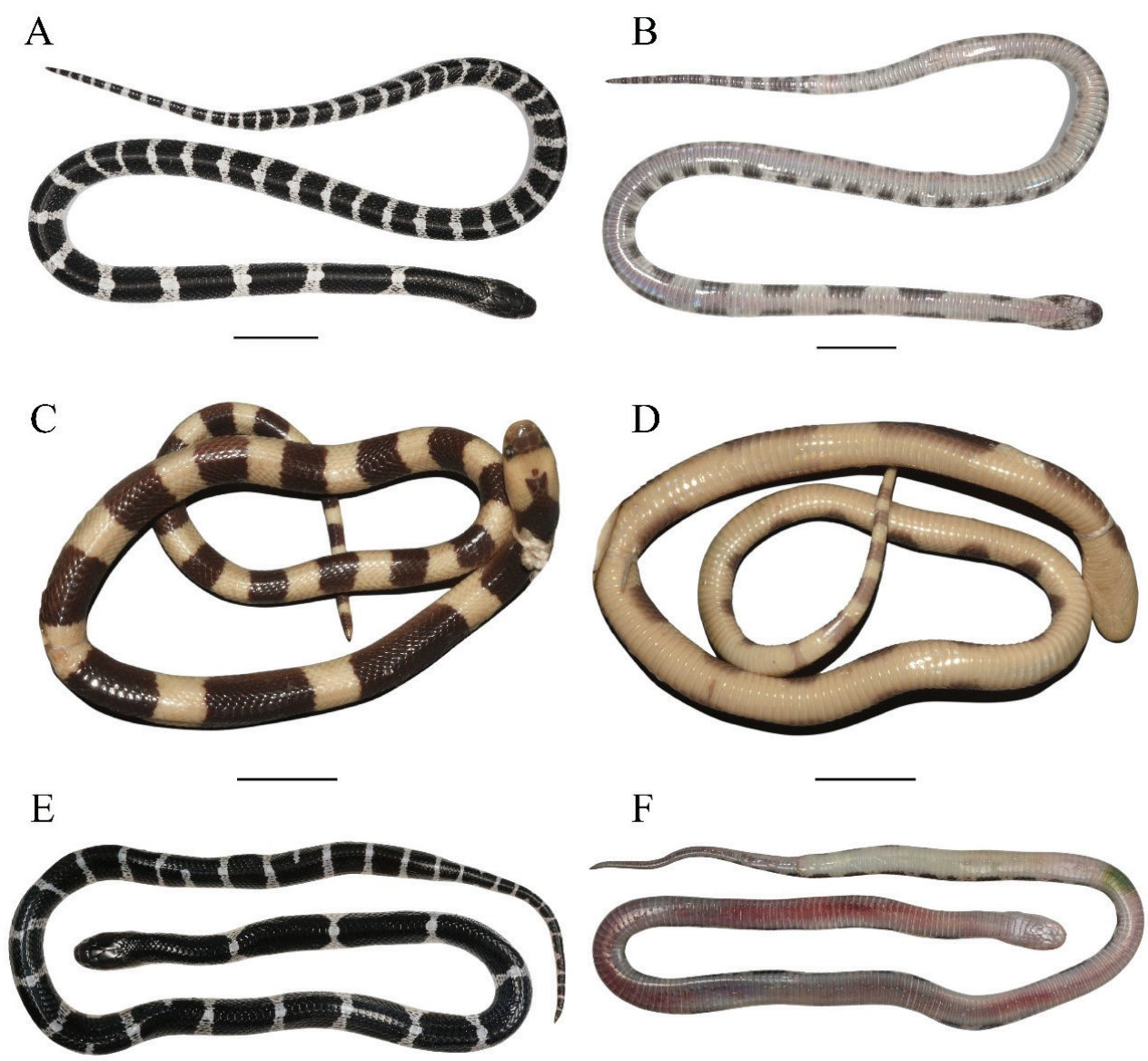

Figure 5. Dorsal (left) and ventral (right) view of juveniles of the Bungarus candidus/multicinctus/wanghaotingi complex A, B B. multicinctus, female, CIB DL18090209 from Fujian, China C, D B. candidus, female, NMW 27730:4 from Tasikmalaya, Java E, F B.wanghaotingi, unknown sex, CIB JCR36 from Jiangcheng, Yunnan, China. Scale bars: $20 \mathrm{~mm}$.

on lateral neck behind parietals for immatures indistinctly edged with white (Fig. 6A); (4) moderately wide black bands on body ( $3-4$ vertebral scales wide) intruding to ventrals for 1.2 to 2 times the width of outer dorsal scales (Fig. 7A); (5) ventral surface of tail with dense black bands and patches (Figs 4B, 5B); (6) posterior maxilla teeth four, distinctly curved backwards (Fig. 8E and Table 3); (7) fangs distinctly curved posteriorly (Fig. 8E); (8) prefrontal suture 1.5-2.5 $(\mathrm{n}=17)$ times length of the internasal suture; (9) VEN 196-236 ( $\mathrm{n}=24)$, NSC 38-58 $(\mathrm{n}=23)$.

Hemipenes description based on a sequenced male (Fig. 9A-C, CIB DL2019051701, SVL 993 mm) from Lishui, Zhejiang, China. Hemipenes reaches $9^{\text {th }}$ subcaudal, bilobed near apex. Base of the organ covered with tiny soft basal hooks, medial portion spinous and apex fully calyculate, with the area between the calyculate 
A

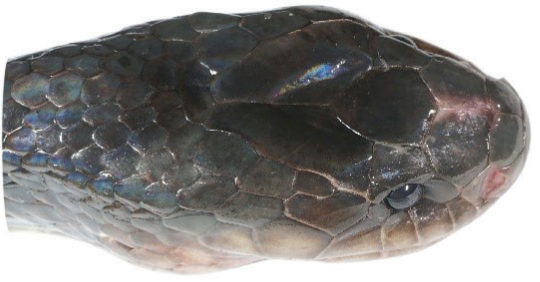

$\mathrm{C}$

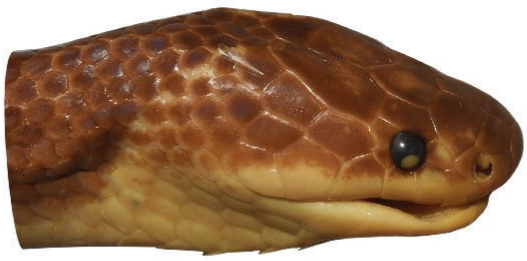

$\mathrm{E}$

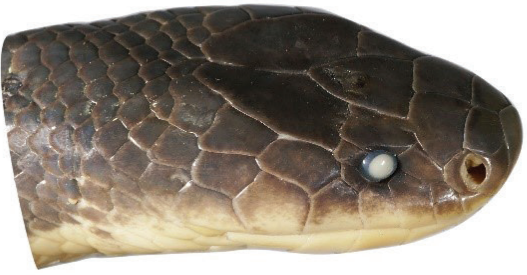

G

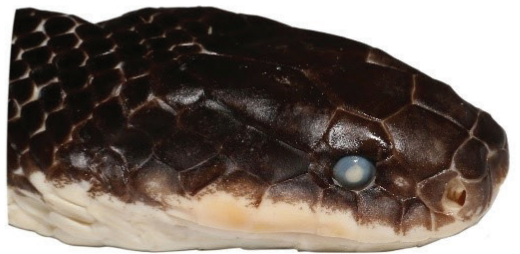

B

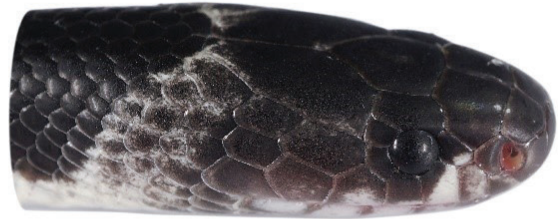

$\mathrm{D}$

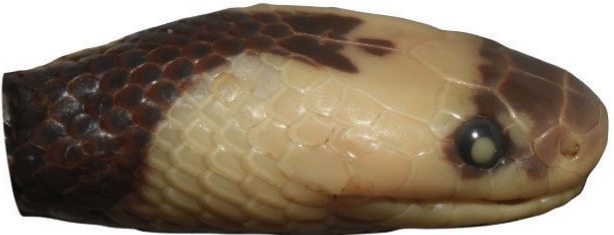

F

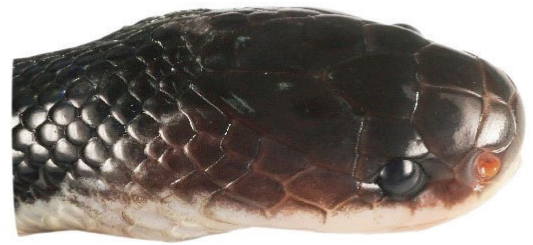

$\mathrm{H}$

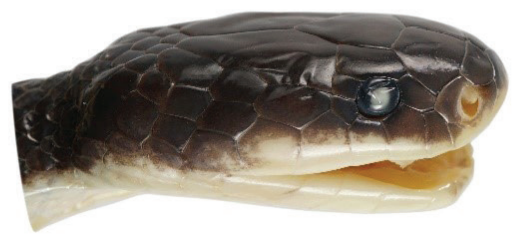

Figure 6. Dorsolateral head view of adults (left) and juveniles (right) of the Bungarus candidus/multicinctus/wanghaotingi complex and B. suzhenae sp. nov. A B. multicinctus, adult male, CIB DL2019051701 from Lishui, Zhejiang, China B B. multicinctus, juvenile female, CIB DL18090209 from Fujian, China C $B$. candidus, adult female, NMW 9486:1 from Pelambang, Java D $B$. candidus, juvenile female, NMW 27730:4 from Tasikmalaya, Java E B. wanghaotingi, adult male, CIB MLML20170801 from Jiangcheng, Yunnan, China F B. wanghaotingi, unknown sex juvenile, CIB JCR36 from Jiangcheng, Yunnan, China G $B$. suzhenae sp. nov. adult female, CIB 116090 H B. suzhenae sp. nov. subadult male, CIB 116088.

zone and spinous zones poorly defined. Most spines on the organ thick, papilla-shaped and blunt, each surmounted by minute, sharp, spine-like tip pointing towards base of hemipenes. The tips are weakly keratinized, concentrated in the shape of short bars; width consistent throughout organ, with a distinct boundary along the region between 
Table 3. Teeth count of some members of subfamily Elapidae in this study.

\begin{tabular}{lcccc}
\hline \multicolumn{1}{c}{ Species } & Maxilla & Palatine & Pterygoid & Dental \\
\hline Bungarus suzhenae sp. nov. $(\mathbf{n}=\mathbf{2})$ & $1+3$ & $10-11$ & $9-10$ & $15-16$ \\
B. candidus & $1+4$ & $/$ & $/$ & $/$ \\
B. wanghaotingi $(\mathbf{n}=\mathbf{1})$ & $1+4$ & $12-13$ & 10 & $16-17$ \\
B. multicinctus $(\mathbf{n}=\mathbf{1})$ & $1+4$ & 12 & 11 & 16 \\
B. fasciatus $(\mathbf{n}=\mathbf{2})$ & $1+3$ & 13 & $11-13$ & 17 \\
Ophiophagus hannab $(\mathbf{n}=\mathbf{3})$ & $1+3$ & $8-9$ & $10-12$ & $15-16$ \\
Naja melanoleuca $(\mathbf{n}=\mathbf{3})$ & $1+2$ & $7-9$ & $13-16$ & $15-16$ \\
N. atra $(\mathbf{n}=\mathbf{3})$ & $1+1$ & $7-8$ & $12-15$ & $14-16$ \\
Sinomicrurus kelloggi $(\mathbf{n}=\mathbf{1})$ & $1+1$ & 8 & 4 & 11 \\
S. macclellandi $(\mathbf{n}=\mathbf{1})$ & $1+0$ & 8 & 9 & 15 \\
\hline
\end{tabular}

the main part of papilla-shaped spines and its tips. The morphology of large spines on hemipenes are similar to the morphology of a male from Changsha, Hunan Province, China, which was described by Pope (1935).

$B$. multicinctus differs from $B$. candidus by having (1) more white bands on the body $(31-50, \mathrm{n}=24$ vs. $18-26, \mathrm{n}=19)$ that are narrower in length $(1-2$ times of length of vertebral scales on middle body vs. 3-5 times); (2) different adult ventral surface (dense brown pigment vs. immaculate white); (3) different coloration of scales on the temporal and lateral neck regions (uniform black in adults and dim white edged in immatures vs. stained white in adults and creamy white in juveniles); (4) shape of the spines on the hemipenis (blunt, papilla-like vs. large spines that are sharp and fangshaped); (5) and by the degree of keratinization of the hemipenial spines (tips of large spines not strongly keratinized, in shape of short bars, with a distinct boundary with the body of large spines vs. tips of large spines strongly keratinized, gradually wider towards base of large spines).

Distribution. This species is known from the following provinces in China based on specimens examined and/or DNA sequences data: Zhejiang, Fujian, Anhui, Guangdong, Guangxi, Hainan, Taiwan, Chongqing and Guizhou. It is also reported from Hunan Province (Pope 1935).

\section{Bungarus wanghaotingi Pope, 1928}

Figs 4E, F, 5E, F, 6E, F, 7E, F, 8D, 9G-I

[English name: Wang's Krait]

[Chinese name: 云南环蛇]

Bungarus multicinctus wanghaotingi Pope 1928: 3.

Bungarus multicinctus wanghaotingi - Mell 1929; Zhao et al. 1998; Zhao 2006

Bungarus wanghaotingi - Leviton et al. 2003

Type locality. Yuankiang, Yunnan, China. Holotype: AMNH 35230.

The typical populations of this species possess the following characters based on 16 examined specimens from Yunnan and Guangxi, China (Appendix 1), squamation 
A

B
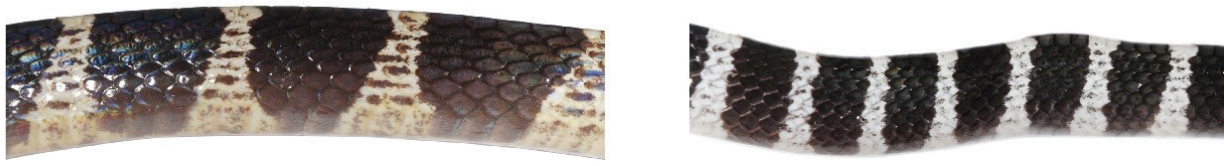

$\mathrm{C}$
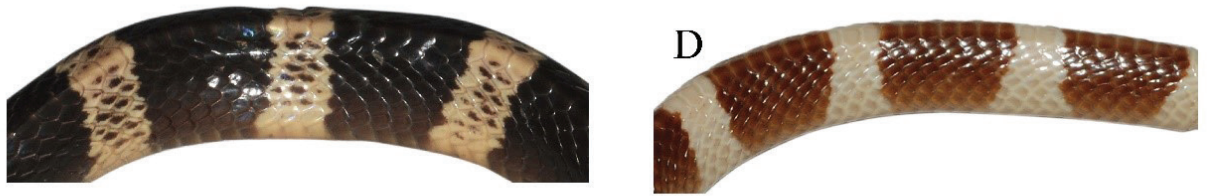

$\mathrm{E}$

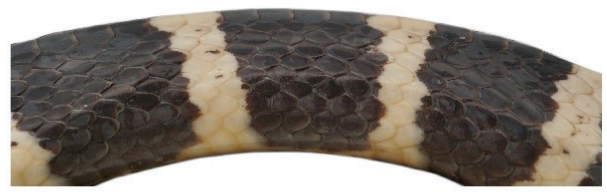

$\mathrm{F}$

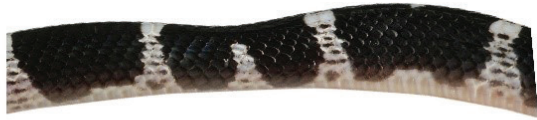

$\mathrm{G}$

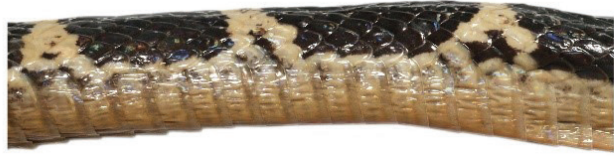

$\mathrm{H}$

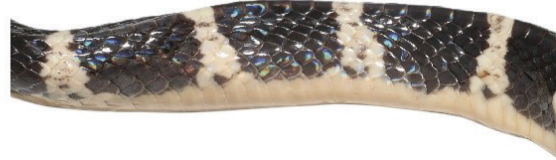

Figure 7. Body patterns of adults (left) and juveniles (right) of the Bungarus candidus/multicinctus/wanghaotingi complex and B. suzhenae sp. nov. A B. multicinctus, adult male CIB DL2019051701 from Lishui, Zhejiang, China B B. multicinctus juvenile female, CIB DL18090209 from Fujian, China C B. candidus, adult male, NMW 27711:1 from Bandong, Java D B. candidus, juvenile male, RMNH 11416 from Pelambang, Java E B. wanghaotingi, adult male, CIB MLML20170801 from Mengla, Yunnan, China F $B$. wanghaotingi, unknown sex juvenile CIB JCR36 from Jiangcheng, Yunnan, China $\mathbf{G}$ B. suzhenae sp. nov. adult male, CIB 116089 from Yingjiang, Yunnan, China $\mathbf{H ~ B}$. suzhenae sp. nov. subadult male, CIB 116088 from Yingjiang, Yunnan, China.

data and body measurements of ten specimens from Yunnan, China (Yang and Rao 2008) and the holotype (Pope 1928): (1) $25.1 \pm 3.2(18-33, \mathrm{n}=27)$ narrow white dorsal body bands, $1.5-2.5(\mathrm{n}=16)$ vertebral scales long at midbody (Yunnan population, $\mathrm{n}=7$; wider on specimens from Thailand) (Figs 4E, 5E); (2) ventral surface immaculate (Figs 4F, 5F); (3) scales on neck and head uniform black in adults, light brown in juveniles (Fig. 6E, F); (4) moderately elongate black bands on body (3.5-6.0 vertebral scales long) intruding to ventrals for 0.5 to 1.5 times of length of outer dorsal scales (Fig. 7E, F); (5) ventral tail white with one row of small light brown dots in the middle of the subcaudals (Figs 4F, 5F); (6) posterior maxilla teeth four, slightly folding backwards (Fig. 8D and Table 3); (7) fangs distinctly curved (Fig. 8D); (8) prefrontals suture 1.2-2.5 $(\mathrm{n}=10)$ times the length of internasals suture; (9) VEN $=209-259$ (n $=23)$, NSC $=32-64(\mathrm{n}=22)$.

The hemipenes (Fig. 9G-I) are described based on the sequenced adult male specimen CIB MLMY20170801 (SVL 1170 mm) from Mengla, Yunnan Province and one 
subadult male CIB DL2019051401 from, Yunnan Province, China; hemipenes reach $9^{\text {th }}$ subcaudal, bilobed near apex, can be divided into three zones similar to $B$. multicinctus, the line of demarcation between the calyculate zone and the spinose zone is poorly defined; large spines thick, relatively short, mostly pointy, gradually thinning from the base to the tip; tips of large spines weakly keratinized, degree of keratinization highest at base, not in shape of short bars and not having a distinct boundary with main body of large spine.

B. wanghaotingi (typical populations from China) differs from B. multicinctus by having (1) fewer white bands on body; (2) ventral colouration of the body (immaculate vs. scattered with dense brown pigments in adults) (Fig. 5A, B); (3) coloration of the ventral surface of tail (immaculate or with dots vs. broad dark bands or patches); (4) the morphology of large spines on the hemipenes (large spines on hemipenes mostly pointy vs. papilla-like in shape and blunt); (5) the shape of the large spines on the hemipenes (without a distinct boundary with main body of large spines vs. with a distinct boundary); (6) fang shape (less distinctly curved vs. distinctly curved) (Fig. 7); and (7) posterior maxilla teeth less folding behind (Fig. 7).

B. wanghaotingi (typical populations from China) differs from B. candidus by having (1) narrower white bands in most specimens; (2) scales on neck and dorsal head uniform black in adults, light brown in juveniles vs. stained white, contrasting with neighbor scales on neck in adults, creamy white in juveniles; (3) ventral tail immaculate or with dots, rather than broad dark bands; (4) large spines on hemipenes relatively short, and weakly keratinized (vs. very elongated, and strongly keratinized).

Distribution. This species is known from the following localities based on specimens examined and/or DNA sequences data: Southern Yunnan, Southern Guangxi, China; Southern, Central and Northern Vietnam; Northern and Central Laos; Southern Thailand.

\section{Bungarus suzhenae sp. nov.}

http://zoobank.org/8F3B0FA6-9B11-4CE3-AAD6-926D159D5220

Figs 6G, H, 7G, H, 8A-C, 9J-K, 10-13

Bungarus multicinctus multicinctus - Yang and Rao 2008, specimen from Yingjiang, Yunnan, China

Type material. Holotype. CIB 116088 (Fig. 9), subadult male, collected from a road through rice fields in Yingjiang County, Yunnan Province, China (97.584451, 24.662632, $922 \mathrm{~m}$ A.S.L), by Ding Li, in 2017. The holotype was a victim of roadkill and was fixed and stored in $80 \%$ ethanol.

Paratypes. One adult male CIB $116089\left(24.466941^{\circ} \mathrm{N}, 97.648691^{\circ} \mathrm{E}, 934 \mathrm{~m}\right.$ A.S.L), one adult female CIB $116090\left(24.634715^{\circ} \mathrm{N}, 97.762291^{\circ} \mathrm{E}, 1559 \mathrm{~m}\right.$ A.S.L), one sub-adult male CIB 116091 from Yingjiang County $\left(24.560296^{\circ} \mathrm{N}, 97.827170^{\circ} \mathrm{E}\right.$, $798 \mathrm{~m}$ A.S.L). The specimens were preserved in $80 \%$ ethanol.

Diagnosis. Assigned to genus Bungarus based on the presence of a row of enlarged, hexagonal scales on the vertebral scale row, enlarged prezygapophyseal accessory pro- 


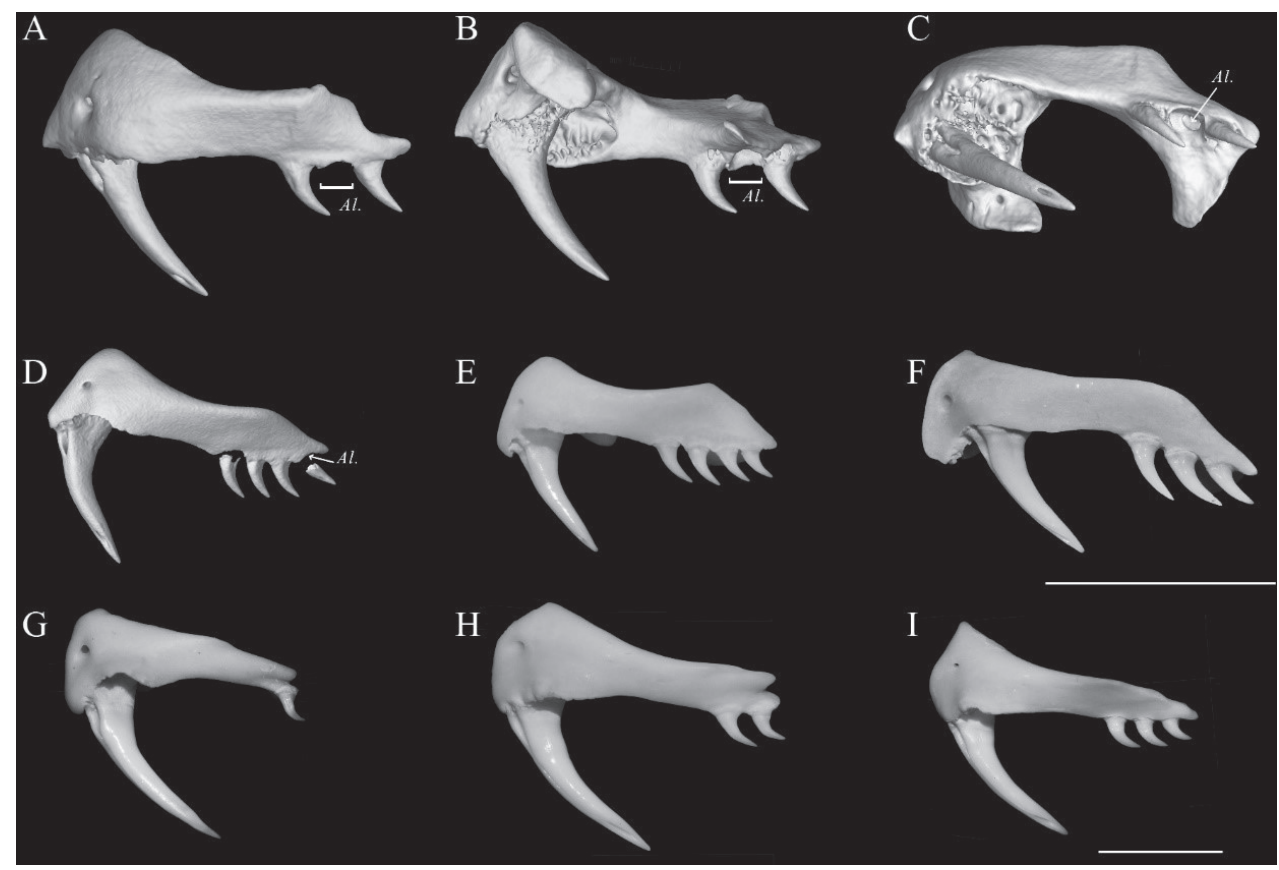

Figure 8. Maxilla morphology of seven members of subfamily Elapidae. Lateral (A) lingual (B), and ventral (C) view of the left maxilla of CIB 116090 (the paratype of B. suzhenae sp. nov.), compared with other members of the subfamily Elapinae D B. wanghaotingi SYNU R170408, from Yala, Thailand E B. multicinctus, from Guangdong, China $\mathbf{F}$ B. fasciatus, from Guangdong, China $\mathbf{G}$ Naja atra from Guangdong, China $\mathbf{H} N$. melanoleuca from Kimpese, Congo I Ophiophagus Hannah from Guangxi, China. Scale bars: $5 \mathrm{~mm}$, note that $\mathbf{H}$ and $\mathbf{I}$ had been scaled down at $1 / 2 . \mathrm{Al}=$ alveoli.

cess and relatively high neural spine (Slowinski 1994). The new species differs from its congeners by having a combination of the following characters: (1) posterior maxilla teeth three, slightly curved behind (Fig. 8A-C); (2) fangs feebly curved; (3) dorsal scales in 15 rows; (4) ventrals 220-229 $(\mathrm{n}=4)$; (5) subcaudals undivided, 51-54 (n =3); (6) anterior chin shields larger than the posterior ones (Fig. 10E); (7) prefrontal suture 2.7-3.4 $(\mathrm{n}=3)$ times length of internasal suture (Fig. 10C, D); (8) adult and subadult heads uniform black (Figs 10-12); (9) dorsal body color black, with $39.3 \pm$ 4.7 (26-38) white narrow bands present on midbody, covering $1.5 \pm 0.4(1.0-2.0)$ vertebral scales; (10) ventral surface uniform white, underside of tail white with tiny brown dots in the middle or immaculate (Figs 10-12); (11) ventral scales connected with the black bands of the dorsal body by small dark patches in lateral view, patches smaller than half the width of a dorsal scale; (12) tail relatively long, TaL/TL = $0.136-0.150(\mathrm{n}=3)$; (13) hemipenes reaching $7^{\text {th }}$ subcaudal; (14) large, elongated and pointed spines on hemipenes, in fang-shaped (Fig. 9J-L); (15) tips of the large spines strongly keratinized, without distinct boundary with the main body of large spines.

Comparison. Comparisons of Bungarus suzhenae sp. nov. with other Bungarus species are shown in Table 1. Bungarus suzhenae sp. nov. differs from B. flaviceps by: (1) 
A

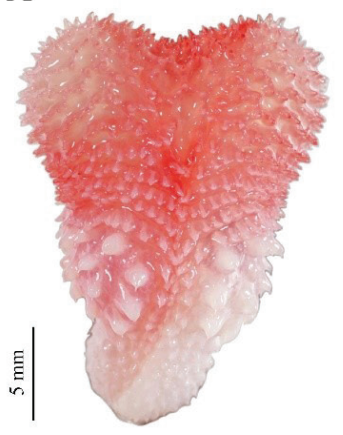

D

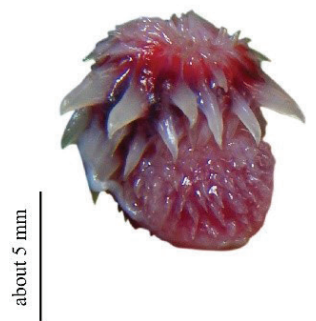

G

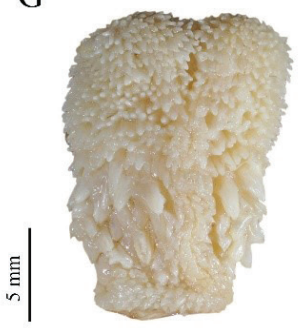

J

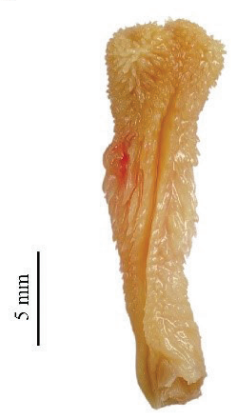

B

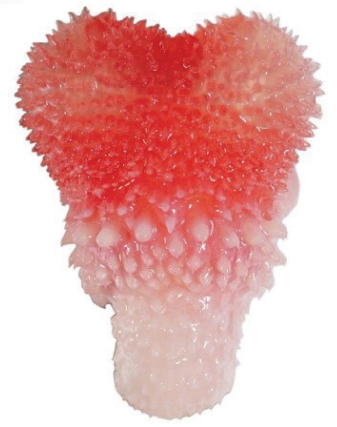

E

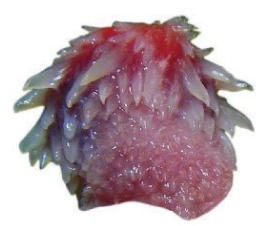

$\mathrm{H}$

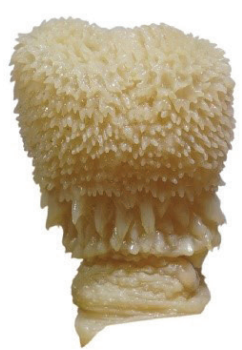

K

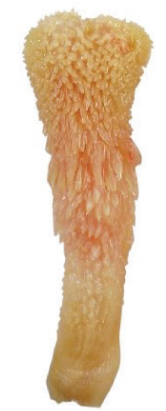

$\mathrm{C}$
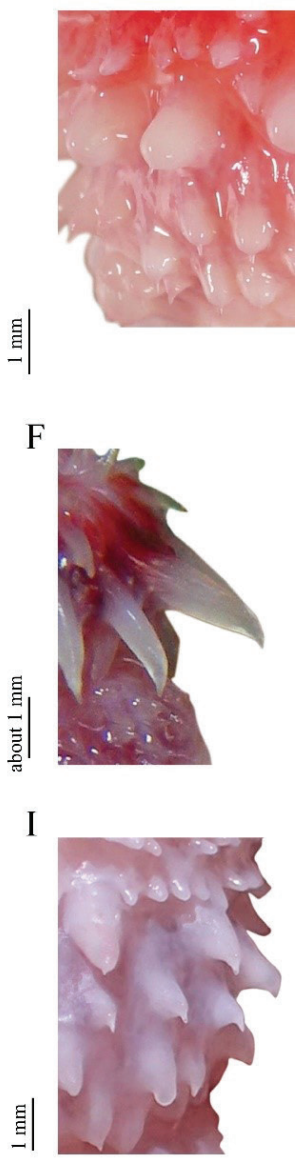

$\mathrm{L}$

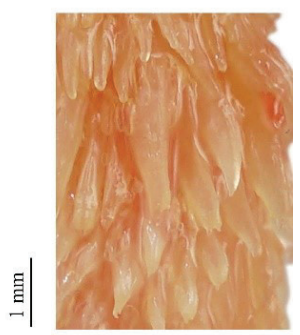

Figure 9. Hemipenial morphology of the Bungarus candidus/multicinctus/wanghaotingi complex and B. suzhenae sp. nov. Sulcate view (left), asulcate view (middle), spines (right) A-C B. multicinctus, CIB DL2019051701 from Lishui, Zhejiang, China, body length 993 mm D-F B. candidus, RH06153 from Quang Binh Province, Vietnam, body length 1200 mm G-I B. wanghaotingi, CIB MLML20170801 from Mengla, Yunnan, China, body length 1170 mm J-L B. suzhenae sp. nov., CIB 116089 from Yingjiang, Yunnan, China, body length $1140 \mathrm{~mm}$. 

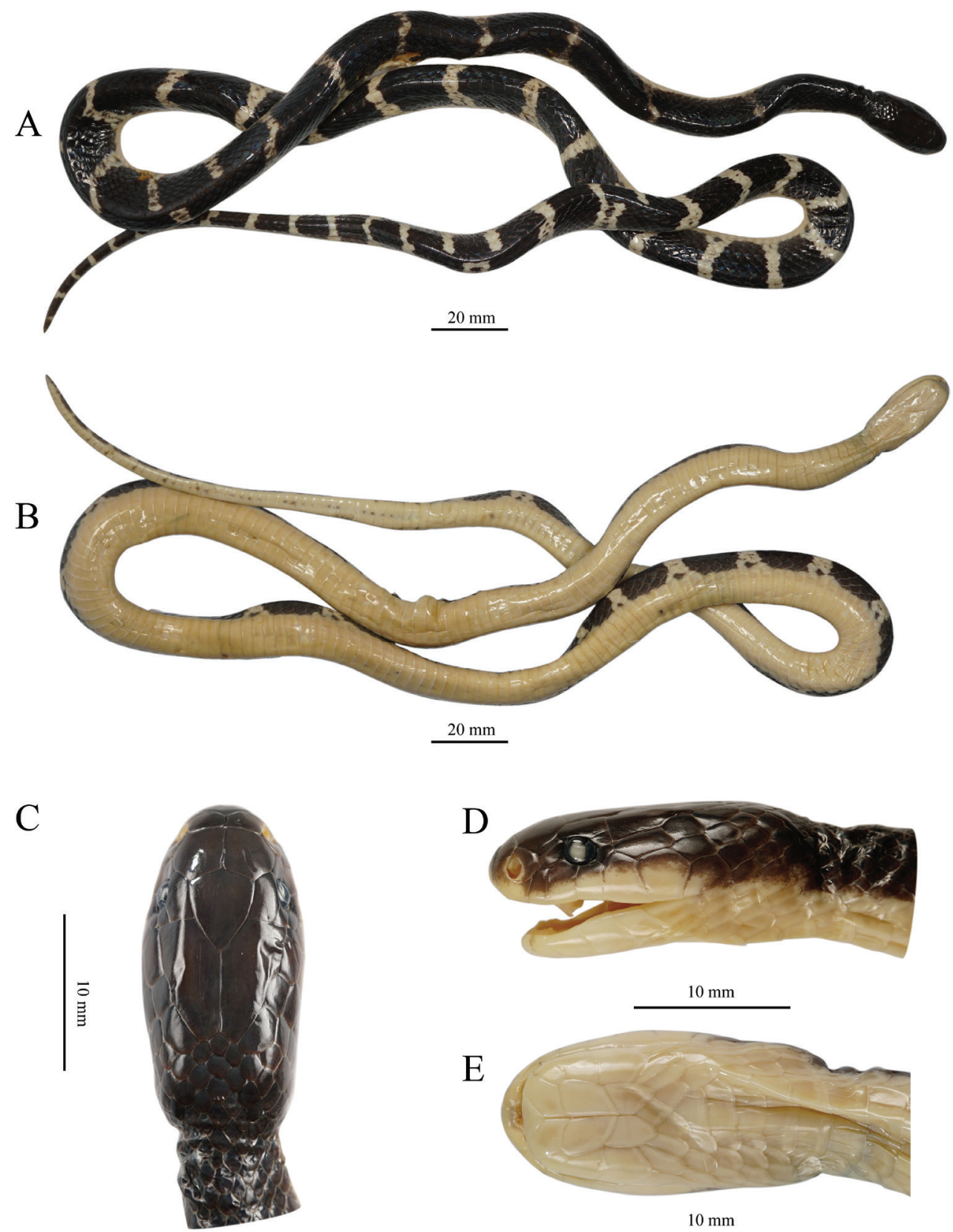

Figure 10. Holotype of Bungarus suzhenae sp. nov. (CIB 116088) A dorsal view of body B ventral view of body $\mathbf{C}$ dorsal view of head $\mathbf{D}$ left lateral view of head $\mathbf{E}$ right lateral view of head.

dorsal scales in 15 rows (vs. 13 rows); (2) dorsal body and tail black with white bands (vs. body black with or without light vertebral and paraventral stripes, tail bright red); (3) head uniform black (vs. head red or yellowish-tan). 


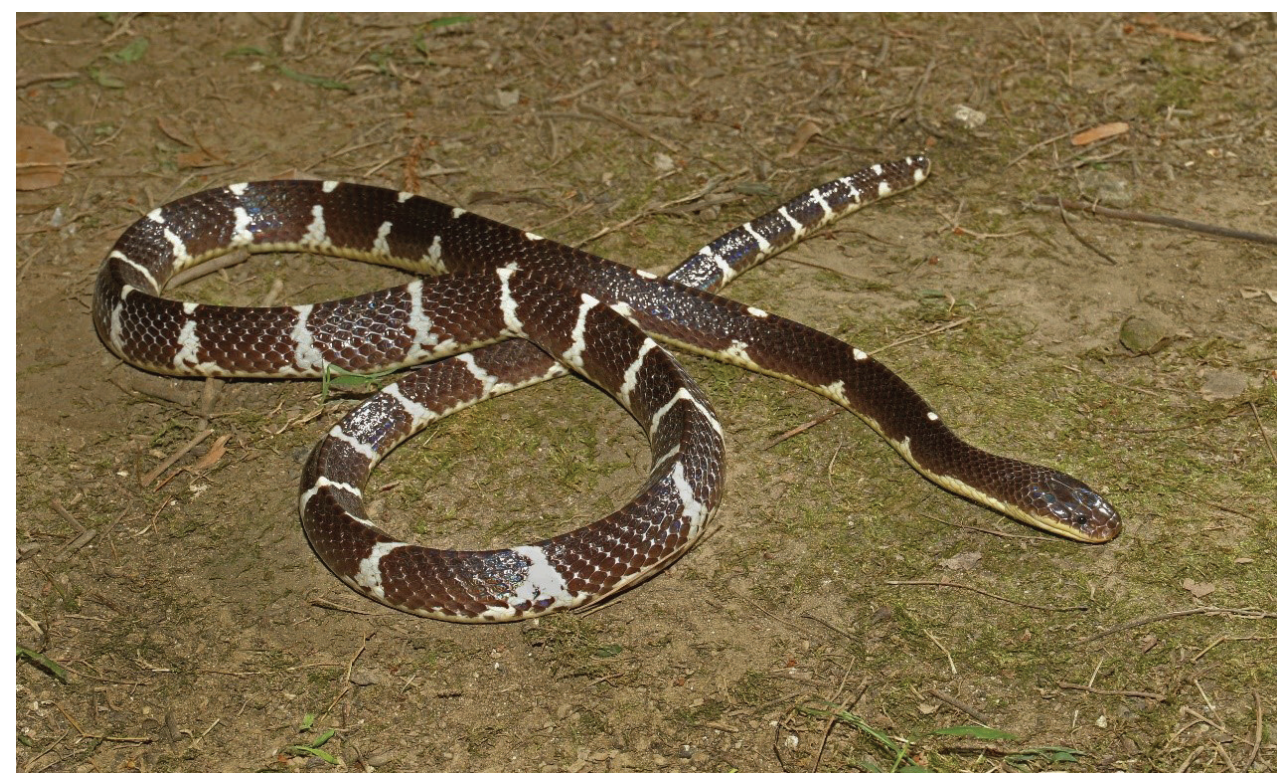

Figure I I. Paratype of Bungarus suzhenae sp. nov. in life (Adult female CIB 116090).

Bungarus suzhenae sp. nov. differs from $B$. fasciatus by: (1) subcaudal scales 51-54 $(\mathrm{n}=3)$ (vs. 23-39, $\mathrm{n}=$ ?); (2) dorsal body black with white bands (vs. with broad yellow rings between the dark rings); (3) dorsal head uniform black (vs. with V-shaped marking on the posterior of the head).

Bungarus suzhenae sp. nov. differs from $B$. bungaroides by: (1) subcaudals undivided (vs. divided); (2) Dorsum with 26-38 white bands (vs. 40-60 narrow white rings composing of small white spots); (3) ventral body uniform white (vs. blackish with irregular yellowish white pattern in every 3 to 4 scale intervals).

Bungarus suzhenae sp. nov. differs from B. slowinskii by: (1) subcaudals undivided (vs. divided); (2) anterior chin shields larger than the posterior chin shields (vs. anterior chin shields similar with posterior chin shields); (3) dorsal head uniform black (vs V-shaped marking present on head); (4) dorsal body and tail with black bands, ventral body uniform immaculate yellowish-white (vs. body with pattern of dark and white rings).

Bungarus suzhenae sp. nov. differs from $B$. ceylonicus by: (1) subcaudal scales 51-54 $(\mathrm{n}=3)$ (vs. 34-40, $\mathrm{n}=$ ?); (2) ventral body uniform immaculate yellowish white (vs. ventral body with broad dark crossbands).

Bungarus suzhenae sp. nov. differs from B. lividus Cantor, 1839 by: (1) vertebral scales distinctly enlarged (vs. only slightly enlarged on the anterior body); (2) subcaudal scales 51-54 ( $\mathrm{n}=3$ ) (vs. 41, $\mathrm{n}=1$ ); (3) dorsal body black with white bands (vs. no bands or rings or with narrow white rings).

Bungarus suzhenae sp. nov. differs from $B$. niger by: (1) dorsal body black with white bands (vs. no bands or rings on body) (Wall 1908); (2) tail relatively longer $(\mathrm{TaL} / \mathrm{TL}=0.136-0.150 \mathrm{n}=3$ vs. $0.132 \mathrm{n}=1)$. 
A
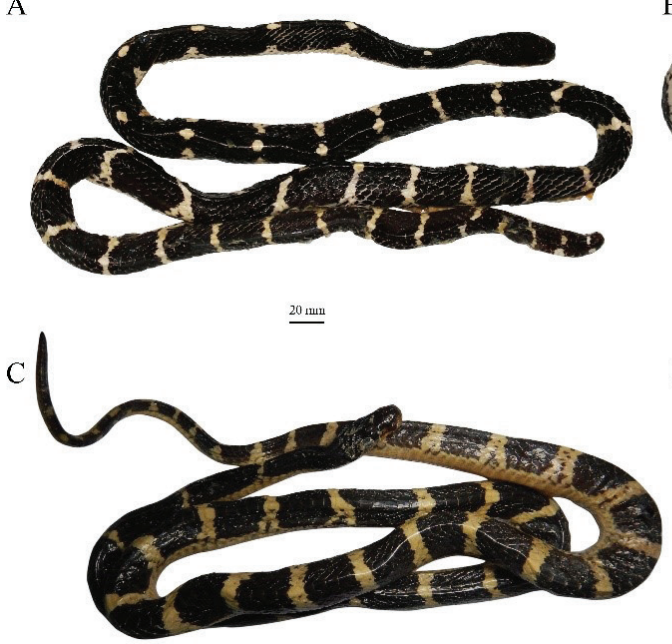

$\underline{20 \mathrm{~mm}}$

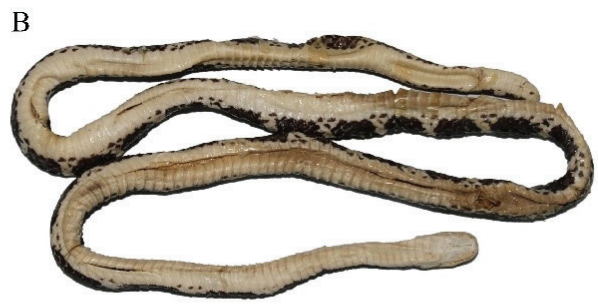

$\underline{20 \Perp 1}$

D

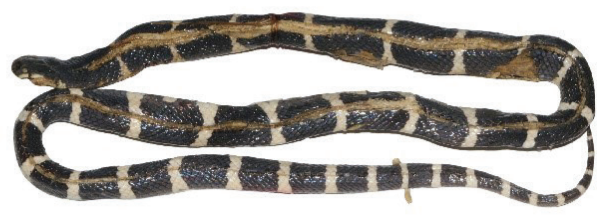

$20 \mathrm{~mm}$

Figure 12. Paratypes of Bungarus suzhenae sp. nov. in preserve A dorsal and ventral B view of adult female CIB 116090 C dorsal view of adult male CIB 116089 D dorsal view of juvenile male CIB 116091.

Table 4. Main characters and measurements of Bungarus suzhenae sp. nov.

\begin{tabular}{lcccc}
\hline \multicolumn{1}{r}{ Character } & CIB 116088 & CIB 116089 & CIB 116090 & CIB 116091 \\
\hline Sex & $\mathrm{M}$ & $\mathrm{M}$ & $\mathrm{F}$ & $\mathrm{M}$ \\
DSR & $15 / 15 / 15$ & $15 / 15 / 15$ & $15 / 15 / 15$ & $15 / 15 / 15$ \\
VEN & 221 & 229 & 222 & 220 \\
SC & 53 & 54 & $11+$ & 51 \\
SL & $7 / 7$ & $7 / 7$ & $7 / 7$ & $7 / 7$ \\
IL & $7 / 7$ & $7 / 7$ & $7 / 7$ & $7 / 7$ \\
BB+TB & $38+12$ & $34+12$ & $34+3+$ & $26+9$ \\
SVL & 620 & 1140 & 1310 & 700 \\
TaL & 109 & 180 & $/$ & 113 \\
HL & 21 & 39 & 30.2 & $/$ \\
HW & 12.3 & 15.5 & 19.4 & $/$ \\
HH & 8.7 & 12.8 & 14.2 & $/$ \\
ED & 9.3 & 10.5 & 14.6 & $/$ \\
\hline
\end{tabular}

Abbreviations. - See in Material and methods.

Note: CIB 116088 is holotype, and other three is paratypes. The tail of CIB 116090 is incomplete. The head of CIB 116091 was flattened by roadkill.

Bungarus suzhenae sp. nov. differs from $B$. magnimaculatus by: (1) more subcaudal scales (51-54 $\mathrm{n}=3$ vs. $40-48)$; (2) dorsum with 26-38 white bands, narrower than black bands in between (vs. 11-14 broad, white crossbars, as wide as the black interspaces).

Bungarus suzhenae sp. nov. differs from B. andamanensis Biswas \& Sanyal, 1978 by: (1) more ventral and subcaudal scales $(220-229 \mathrm{n}=4$ and $51-54 \mathrm{n}=3$ vs. $192-197 \mathrm{n}$ $=4$ and $45-47 \mathrm{n}=4) ;(2)$ a shorter tail $(\mathrm{TaL} / \mathrm{TL}=0.136-0.150 \mathrm{n}=4$ vs. $0.155-0.16$ $\mathrm{n}=4$ ); (3) dorsum with 26-38 white bands (vs. 44 white linear arches or bars, mottled with brown); (4) head uniform black (vs. head is chocolate); (5) ventral body uniform white (vs. anterior and lateral margin of ventral scales tinged with brown). 
Bungarus suzhenae sp. nov. differs from B. sindanus by: (1) fewer dorsal scale rows (15 vs. 17); (2) dorsal body colouration (black with white crossbands, and bands mostly complete vs. black with crossbands formed by series of white spots and interrupted).

Bungarus suzhenae sp. nov. differs from B. walli Wall, 1907 by: (1) fewer dorsal scale rows (15 vs. 17 rows); (2) dorsal body coloration (black with white crossbands, and bands mostly complete vs. body black above with crossbands formed by series of white spots and interrupted); (3) a higher number of ventral scales (220-229 $\mathrm{n}=4 \mathrm{vs}$. $198-207 \mathrm{n}=8$ ).

Bungarus suzhenae sp. nov. differs from B. persicus Abtin, Nilson, Mobaraki, Hooseini \& Dehgannejhad, 2014 by: (1) fewer dorsal scale rows (15 vs. 17); (2) fewer ventral scales $(220-229 n=4$ vs. 236-238 $n=2)$; (3) loreal plate absent (vs. present); (4) dorsal body coloration (black with white bands vs. body with crossbars ending in pairs of small rectangular whitish dots or short crossbars).

Bungarus suzhenae sp. nov. differs from B. caeruleus by: (1) dorsal body coloration (black with white crossbands, and bands mostly complete vs. narrow transverse white streaks or with small white spots); (2) white bands not in pairs (vs. at least some white bands occurring in pairs).

Bungarus suzhenae sp. nov. is morphologically most similar to phylogenetically closest congeners in B. candidus/multicinctus/wanghaotingi complex. However, it differs from the latter by multiple morphological characters. See hemipenis and maxilla comparisons in Tables 2, 3. The new species differs B. multicinctus by: (1) fang shape (less distinctly curved vs. distinctly curved); (2) lesser posterior maxilla teeth (three vs. four); (3) relatively longer prefrontals suture (length 2.7-3.4 times of internasals suture $\mathrm{n}=3$ vs. $1.3-2.3$ times, $\mathrm{n}=16$ ); (4) ventral body coloration in adults (immaculate white, $\mathrm{n}=4$ vs. white scattered with dense brown pigments, $\mathrm{n}=19$ ); (5) black bands on body (large, length 4-7 times of vertebral scales on middle body, not reaching ventrals or just stained the edges of it, ventrals with black edges smaller than half of outer dorsal scales vs. black bands on body moderate, length 3-4 times of vertebral scales, intruding to ventrals for 1.2 to 2 times of width of outer dorsal scales); (6) ventral tail colouration (white with tiny brown dots in the middle or immaculate vs. with dense black bands or patches); (7) relatively shorter hemipenis (reaching $7^{\text {th }}$ subcaudal vs. $9^{\text {th }}$ subcaudal); (8) shape of large spines on hemipenes (elongated, fang-shaped, pointy vs. papilla-like and blunt); (9) tips of large spines on hemipenis (strongly keratinized, without distinct boundary with the main body of large spines vs. weakly keratinized, in shape of short bar, with a distinct boundary with main body of large spine).

Bungarus suzhenae sp. nov. differs $B$. candidus by: (1) fewer posterior maxilla teeth (three vs. four); (2) white bands on dorsal body more and narrower (26-38 white bands on dorsal body, width covering 1.0-1.5 vertebral scales on middle dorsum, $\mathrm{n}=4$ vs. 19-26 white bands on dorsal body, width covering 3.0-5.0 vertebral scales, $\mathrm{n}=18$ ); (3) prefrontal suture relatively longer (2.7-3.4 times length of internasals suture, $\mathrm{n}=3$ vs. 1.4-2.4 times, $\mathrm{n}=17$ ); (4) coloration on the upper head surface and neck (uniform black on adults and juvenile vs. temporal area and lateral neck light brown in adults, lateral necks and dorsal head posterior to eyes of immatures creamy white; (5) ventral tail 
colouration (white with tiny brown dots in the middle or immaculate vs. with broad dark crossbands); (6) black bands on body (not intruding to ventral body, ventrals with narrow black edges smaller than half of outer dorsal scales vs. intruding to the ventral body, narrow black edges on ventrals with width 1-2 times of outer dorsal scales).

Bungarus suzhenae sp. nov. differs from typical $B$. wanghaoting $i$ by: (1) slightly curved fangs (slightly curved and arc-like vs. distinctly curved); (2) fewer posterior maxilla teeth (three vs. four); (3) shorter hemipenis (reaches $7^{\text {th }}$ subcaudal vs. $9^{\text {th }}$ subcaudal); (4) shape of large spines on hemipenis (elongated, fang-shaped (vs. relatively short and blunt); (5) the degree of keratinization of the large hemipenial spines (strongly keratinized vs. weakly keratinized).

Description of holotype. (Fig. 10). Subadult male. Head relatively long, length $21.0 \mathrm{~mm}$, maximal head width at anterior temporals $12.3 \mathrm{~mm}$; maximal head height $8.7 \mathrm{~mm}$, head 1.7 times longer than wide, distance between eyes $9.3 \mathrm{~mm}$. Body length $620 \mathrm{~mm}$; tail complete, $109 \mathrm{~mm}$; total length $729 \mathrm{~mm}$.

Body scalation. Ventrals 221, preventrals 3, anterior edge of first ventral starting at level of oral rictus; azygous scale immediately anterior to cloacal scale, half in width of the ventrals. Cloacal plate undivided. Subcaudals 53 undivided, tail complete. Dorsal scales smooth, in 15-15-15 rows; vertebral scales distinctly enlarged, largest and hexagonal at midbody, slightly wider than long.

Head. Cephalic scales smooth. Rostral near $\Lambda$-shaped, width 1.6 times of height visible from above. Nasals large, constricted and divided into one prenasal and one postnasal on both sides at border with internasals and first supralabial, prenasals irregular-shaped while postnasals crescent-shaped. External nares large, vertical oval-shaped, slightly smaller than eye diameter. Postnasal-preocular suture short and straight. Preocular hexagonal, bordered by third and fourth supralabials. Internasals two, 1.1 times wider than long, in contact with rostral, prenasals and postnasals, preoculars, and prefrontals. Prefrontals large, slightly wider than long; internasals suture short, prefrontals suture length 2.9 times of internasals suture and not aligned with latter. Frontal shieldshaped, pointing posteriorly, 1.3 times longer than wide, bordered by prefrontals, supraoculars and parietals; anterior suture of frontal pointed toward prefrontal suture, dividing posterior ends of prefrontals; supraoculars small, 1.7 times longer than wide, in contact with preoculars, upper postoculars, prefrontals, frontal and parietals. Parietals large and long, distance between end of parietals to preoculars 1.5 times the length of frontal; bordered by frontal, supraoculars, upper postoculars, one anterior temporal and two upper posterior temporals on each side, and three smalls nuchal scales on posterior margins. Posterolateral margins of parietals bordered by $1 / 1$ enlarged elongate scales that anteriorly contact upper posterior temporals. Posterior extension of parietals pointed, divided in the middle by one of those three small dorsal scales. Preoculars $1 / 1$, long hexagon, bordering with postnasal, second and third supralabials, prefrontal, and supraocular. Eyes small, oval, horizontal diameter $2.3 \mathrm{~mm}$, vertical diameter $1.9 \mathrm{~mm}$. Postoculars $2 / 2$; relatively small with half size of preoculars; each lower postocular bordered by fourth and fifth supralabials, orbit, anterior temporal, upper postocular; each upper postocular bordered by lower postocular, orbit, supraocular, parietal but 
not anterior temporal. Anterior temporals 1/1, long and hexagonal, length 2.9 times of width; each bordered by fifth and sixth supralabials, lower postocular, parietal, posterior temporals. Posterior temporals $2 / 2$, bordering parietals, anterior temporals, sixth and seventh supralabials, and enlarged elongate scales bordering posterolateral margin of parietals. Supralabials $7 / 7$, the third and fourth supralabials forming lower margin of orbit; first supralabials small, triangular, with pointed extension behind, not reaching preoculars, 1.4 times higher than wide; other supralabials in different subpentagonal shapes; second supralabials long and pentagonal-shaped, larger than the first, 1.8 times higher than wide; third supralabials larger than the former two, and the fourth, 1.5 times higher than wide; the fourth supralabials more or less rectangular, 1.6 times higher than wide; fifth and sixth supralabials are among the two largest, both 1.1 times higher than wide and similar in size, but fifth supralabials wider at lower part while the sixth supralabials is wider at the upper part; seventh supralabials height equal to width. Mentals moderate, width slightly shorter than width of rostral, triangular, bordering first infralabials, mental groove distinct. Infralabials 7/7 first infralabials pentagonalshaped, long and narrow, in broad contact behind the mental and anterior chin shields; second infralabials in form of a square, half size of the first; the third and fourth enlarged; first, second, and third infralabials in broad contact with anterior chin shields, fourth infralabials in broad contact with posterior chin shields. Anterior chin shields larger than the posterior chin shields, the two pairs of chin shields in form of butterfly wings; anterior chin shield suture 3.5 times the length of the posterior chin shield suture; posterior chin shields 1.6 times longer than wide, bordered by anterior chin shields, fourth infralabials, 2/2 sublabials, and three gulars. Four gulars between first ventral and posterior most extension of each posterior chin shield; one gular and three preventrals between first ventral and suture of posterior chin shields, preventrals wider than half of first ventrals, gradually larger from first preventral to third.

Coloration in preservative. Dorsal surface of head, upper part of sides of the head, including upper part of supralabials, uniform black; lower half of head, including lower part of supralabials and rostral yellowish-white; ventral head uniform yellowish-white; iris dark black.

Dorsal body black with 38 white narrow crossbands (including incomplete bands). White bands on body scattered with tiny dark patches. Length of bands 1.0 to 2.0 times vertebral scales (average $1.2 \pm 0.2$ ), bands widening on flanks before joining the ventral surface, which is uniform white. 10 out of 38 bands incomplete, only present on one side of the dorsal body. First band starts at the $13^{\text {th }}$ ventral, nine vertebral scales between first and second band; following bands gradually denser and brighter, three vertebral scales between $37^{\text {th }}$ and $38^{\text {th }}$ band. Most bands wider on outer row of dorsal scales, a dark spot present at junctions where the white bands meet the ventrals; black bands on body wide, covering 5-6 vertebral scales on middle body, not intruding to venter, ventrals with narrow black edges smaller than half of lateral dorsal scales. Venter immaculate yellowish-white, lateral edges of ventrals between dorsal white bands black.

Dorsal surface of tail black; 12 immaculate white bands present on dorsal part, width about equal to the width of one vertebral. Ventral portion of tail yellowish white, 
23 of intermittent subcaudals with small brown dots; subcaudals between white bands margined with brown laterally (Fig. 10).

Variation. Paratypes largely resemble the holotype in scalation and color but differ in the following characters: upper postoculars of one adult male (CIB 116090) and one subadult male (CIB 116091) bordered by the anterior temporal on both sides. Ventral tail of CIB 116089, CIB 116090 (for remaining part) and CIB 116091 immaculate instead of mottled with small dots. First to $10^{\text {th }}$ and the $12^{\text {th }}$ white crossbands on dorsum of CIB 116090 disconnected, forming moderate white dots covering two vertebral scales. Posterior chin shields suture of CIB 116090 barely exist. The dorsal bands are fewer in CIB 116091 (Fig. 12).

Cranial osteology. The premaxilla of $B$. suzhenae sp. nov. is quite small and blunt, the ascending process of the premaxilla is well-developed, meeting the nasals at its dorsal edge. The nasal process of the premaxilla is not conspicuous. The nasal is peltate, with a blunt process on the lateral margin. The mesial process of the prefrontal is quite slender and pointed, narrowly reach the anterior tip of the frontal. Frontal triangular in shape from dorsal view. The distal process of the postorbital is slender and slightly anteriorly pointed, the basal part is in contact with the posterolateral marge of the frontal. A fenestra notch present on the posterolateral marge of the frontal. Two sides of the anterior surfaces of the parietal form the angle of approximately 120 degrees. The parietal is approximately " $T$ " shaped; the lateral process is conspicuous and rectangular. The dorsal ridge of the parietal is more conspicuous in adults than in juveniles. The posterior end of the dorsal ridge merges at the mesial of the parietal in adults whereas separated in juveniles. The prefrontal surface of maxilla conspicuously upheaved. The supratemporal is flexed whereas the angular surface to the quadrate is obviously incrassated. The quadrate is quite short and stubby, the anterior angular surface to the supratemporal is extended. The ventral process of the basioccipital is trifurcate. The maxilla process (lateral process) of the palatine quite small whereas the choanal process is absent. The pterygoid is slender and medially curved, with the ectopterygoid process lost. The compound bone is quite stocky, the mesial crest and lateral crest are low and inconspicuous.

The first fang is canaliculated and feebly curved behind. There are four or five replacement fangs posterior to the first. Three small solid teeth ranged on the posterior end of maxilla, decrease in size posteriorly and separated from the fang by a very large diastema. Palatine teeth 10 (11), pterygoid teeth 10 (9); dentary teeth 16 (15), 2, 3 and 4 largest, decrease in size posteriorly. (Fig. 13).

The DOI numbers for ADMorph: 10.12112/R.0003 (CIB 116088, holotype) and 10.12112/R.0004 (CIB 116090, paratype).

Hemipenes. Description is based on the adult male paratype CIB 116089 (Fig. 9J-L; SVL 1,140 mm). Hemipenis reaches $7^{\text {th }}$ subcaudal, slightly bilobed near top. Three zones of similar length of ornamentation exist: a distal calyculate zone, a spinose zone proximal to the sulcus bifurcation, and a basal zone. The line of demarcation between the calyculate zone and spinose zones is poorly defined. The 


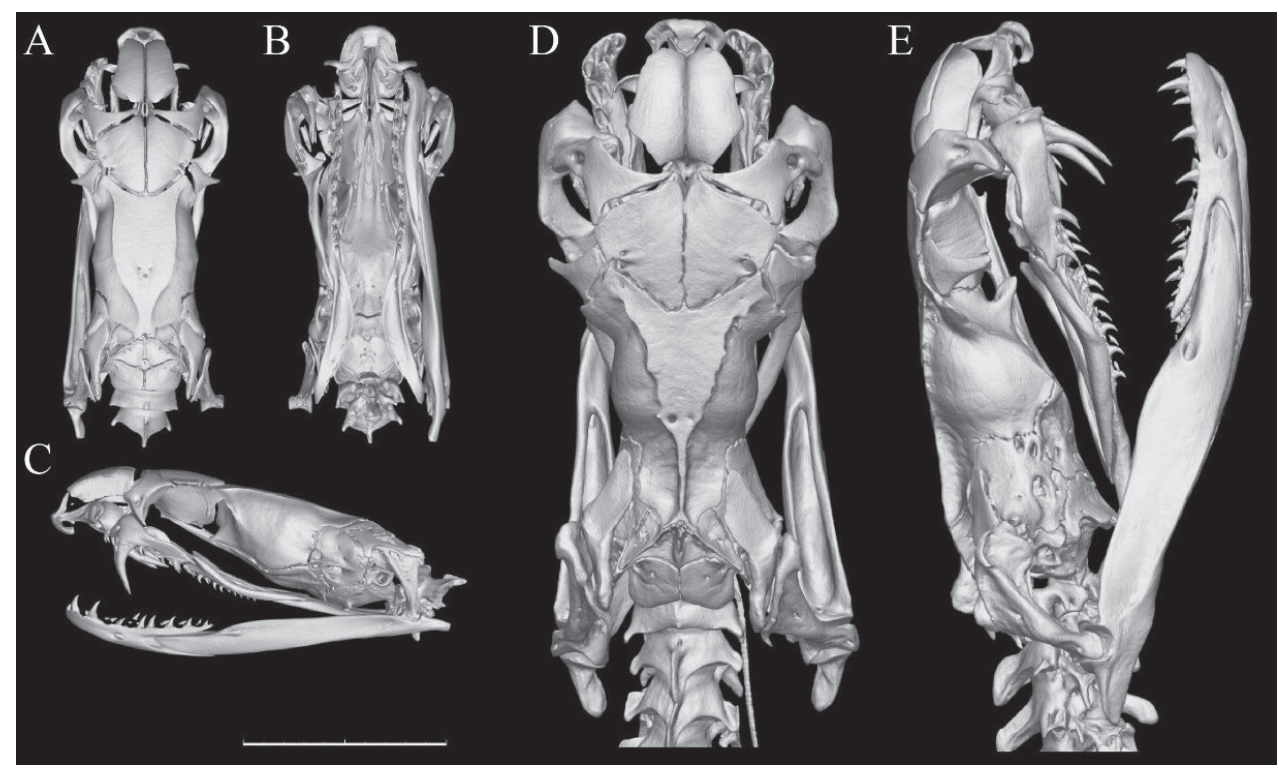

Figure 13. Three-dimensional reconstructed skull models of the holotype (A-C CIB 116088, subadult male) and paratype (D, E CIB 116090, adult female) of Bungarus suzhenae sp. nov. Dorsal (A, D), ventral (B), lateral (C, E) view. Scale bar: $10 \mathrm{~mm}$.

calyculate zone is capitate; calyces well developed, gradually smaller and lesser keratinized towards the distal end; calyces nearest the sulcus intruding to the spinous zone by few ranks. The spinose zone is covered with large spines; large, elongated and pointed spines on hemipenes, in fang-shaped, gradually thinner from bases to tips; tips of large spine strongly keratinized, without distinct boundary with the main body of large spines; the spines adjacent to the calyces are nearly twice as large as the most proximal ones in a sulcate view. The hemipenis slightly constricts between the spinose zone and the basal zone. The basal zone is covered with numerous minute spines on the larger distal part, and smooth proximal region. The sulcus is forked distally along the spinose zone, with the bifurcation originating at a distance of about one large spine length; lips bearing calyces in calyculate zone, and small spines throughout the spinose region.

Etymology. The specific epithet of the new species was named after Su-Zhen Bai, a famous powerful goddess of Chinese myth The legend of the White snake (白蛇传), in honor of her courage to true love and kindness to people. The common name is suggested as "Suzhen's krait" in English and “素贞环蛇 (sù zhēn huán shé)" in Chinese.

Distribution and ecology. Bungarus suzhenae sp. nov. was found in rice fields, streams in monsoon forest at elevation from $800 \mathrm{~m}$ to $1,560 \mathrm{~m}$. This species is distributed in Yingjiang Country, Yunnan Province, China and Kachin State, Myanmar (Fig. 1). In captivity, they prey on eels like Monopterus albus and small snakes such Xenochrophis flavipunctatus, Pareas spp., but refuse mice and frogs. 


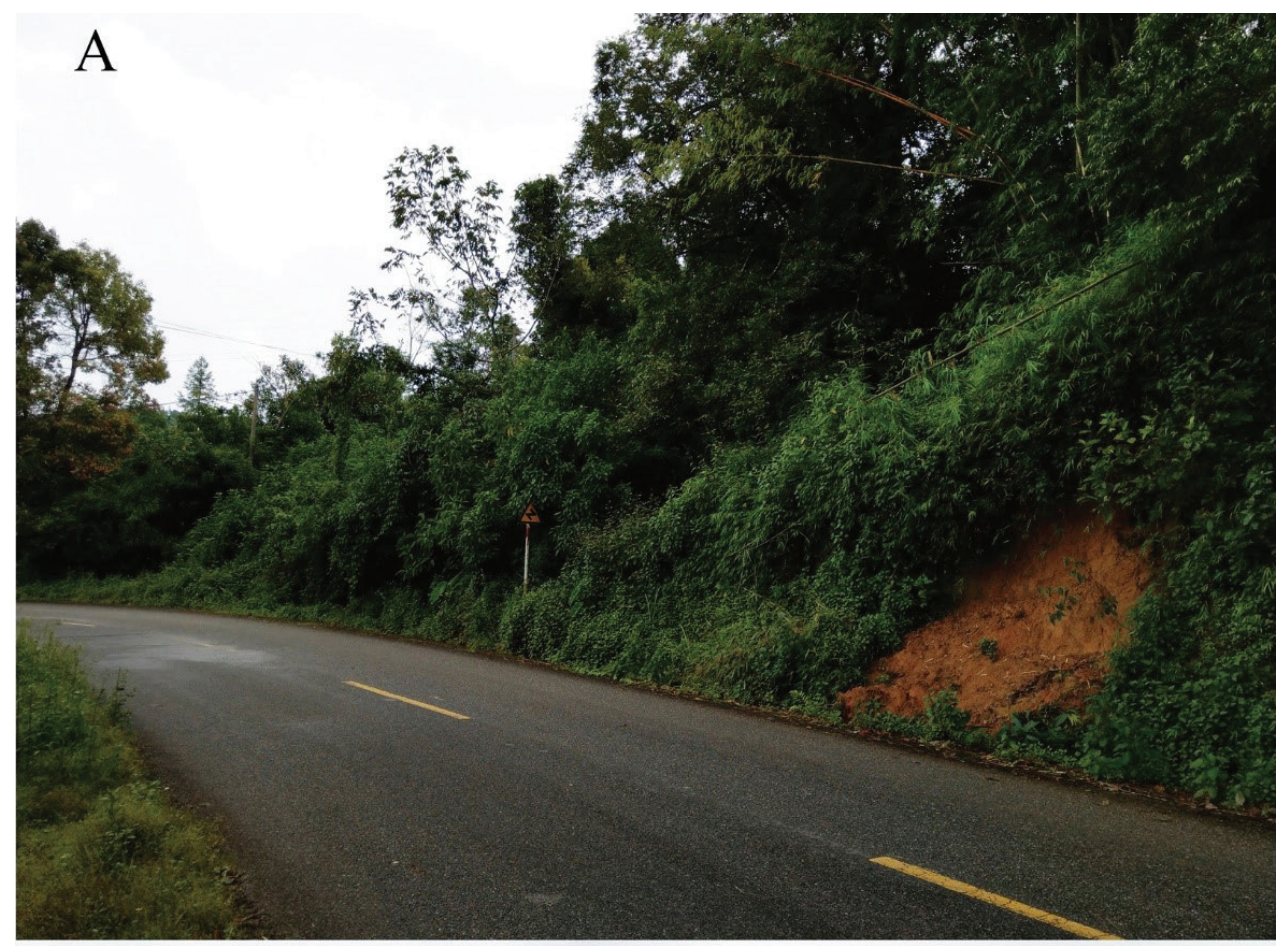

B

1

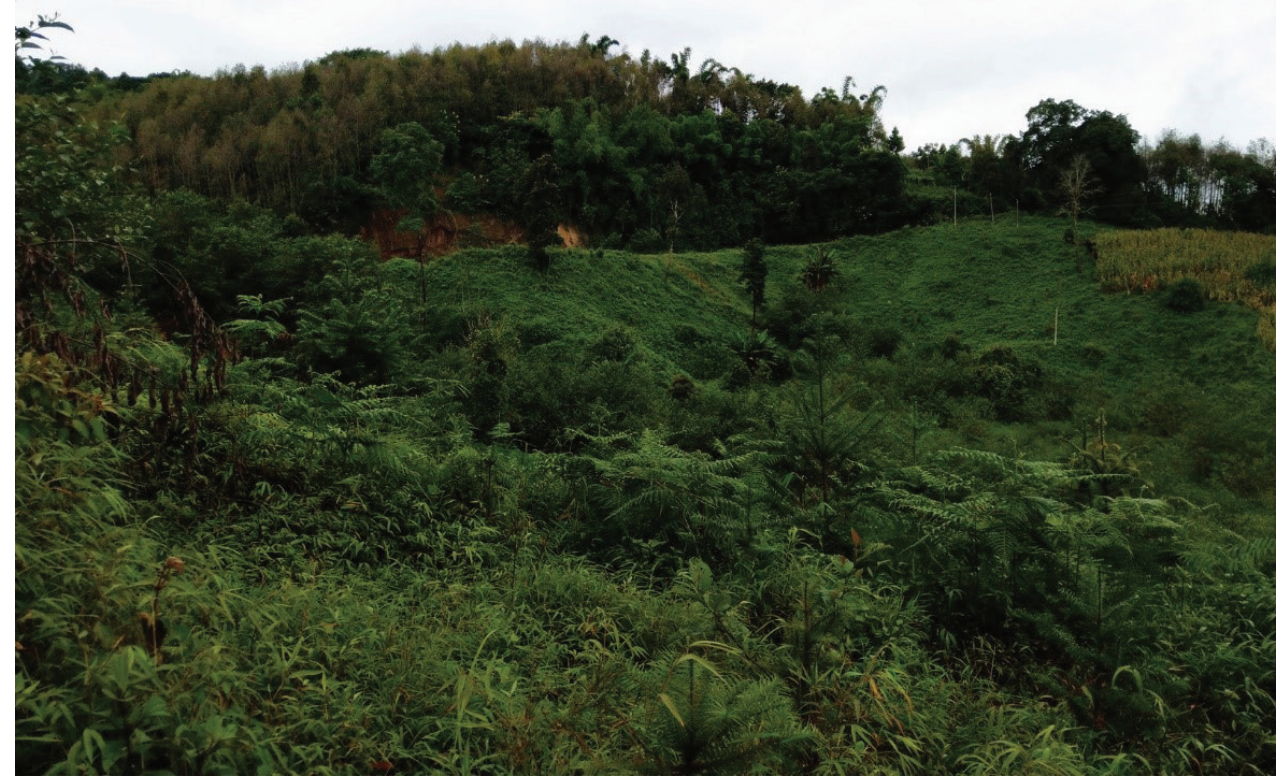

Figure 14. Habitats of Bungarus suzhenae sp. nov. Road A in Yingjiang County, Yunnan Province, China. Monsoon forest B in Yingjiang County, Yunnan Province, China. 


\section{Discussion}

Since the members of Bungarus are a group of deadly snakes, understanding their species diversity, species boundaries and geographic distribution is vital for saving human lives. Snakebites from kraits are known to have a high mortality, and the toxicology of their venom has been the subject of numerous publications (e.g., Mebs et al. 1971; Liu et al. 1998; Chang et al. 1999; Nirthanan et al. 2002; Jiang et al. 2011). An extreme and sad case for krait bites is that one individual of Bungarus suzhenae sp. nov. (CAS 221526) led to the death of famous herpetologist Joe Slowinski (Justin L. Lee 2020; personal communication). Many studies have indicated that the venom composition of $B$. candidus is different from B. multicinctus (e.g., Nirthanan et al. 2002; Tsai et al. 2002). Thus, a sound understanding of the species boundaries between these two species is necessary to provide the essential underpinnings for future research on their venom composition and antivenin development (Fry et al. 2003; Barlow et al. 2009; Williams et al. 2011; Casewell et al. 2013, 2014). However, identification of these Bungarus is still challenging. Our examination of the specimens from the B. candidus/multicinctus/wanghaotingi complex shows that the traditional characters used to diagnose the three taxa from each other (i.e., by the number of the white/black bands and the ventral scales) only work for $B$. candidus and $B$. multicinctus. Furthermore, the range of the white body bands of $B$. wanghaotingi overlaps with that of $B$. candidus and $B$. multicinctus (Table 1 ) and may be unreliable for identification without further examination of other characters. As for $B$. suzhenae sp. nov., the range of the number of crossbands also overlaps with that of the $B$. candidus/multicinctus/wanghaotingi complex except B. candidus (Table 1).

Thorough morphological examination and comparisons are essential for taxonomy of $B$. candidus/multicinctus/wanghaotingi complex. The topology of molecular phylogeny in Xie et al. (2018) is similar to the topology in this study. The samples from Java, Indonesia, Thailand, and Vietnam form a lineage ( $B$. candidus lineage) sister to the lineage (B. wanghaotingi lineage) including samples from southwestern and southern China, Laos, Thailand and Vietnam. However, Xie et al. (2018) concluded that the latter lineage is $B$. candidus without morphological comparisons with typical $B$. candidus from Indonesia and Peninsular Malaysia. Thus, the distribution report of "B. candidus" in the southwestern and southern China mentioned by Xie et al. (2018) should be revised into B. wanghaotingi. And similarly, the records of "B. multicinctus" in Vietnam, Laos, and Thailand (Uetz and Hošek 2017) are supposed to be B. wanghaotingi.

The "B. candidus" from Southern and Central Vietnam mentioned by Nguyen et al. (2017) are paraphyletic based on COI sequences data when B. candidus from Peninsular Malaysia (SYNU R180411, which is monophyletic with Javanese $B$. candidus in cyt $b$ phylogeny) is included. Most specimens (e.g., ITBCZ 900) are monophyletic with typical B. wanghaotingi from China, Laos and Southern Thailand. But one specimen (KIZ 100 ) is monophyletic with two B. candidus from Peninsular Malaysian and Cambodia. This suggests a large sympatric zone from Southern Thailand to Southern Vietnam where B. wanghaotingi and B. candidus are morphologically similar in having wide crossbands but genetically paraphyletic (Fig. 1; Nguyen et al. 2017). However, the hemipenial mor- 
phology of wide crossbanded B. wanghaotingi ITBCZ 900 (fig. 3 in Nguyen et al. 2017) is quite similar with typical $B$. wanghaotingi by large spines on hemipenes relatively short, and weakly keratinized. Southern Indochina populations of $B$. wanghaoting $i$ have wider crossbands on body than typical B. wanghaoting $i$ in the north and this is possibly due to different selective constraints from habitats at lower latitude. This is similar to the discussion on B. candidus and B. javanicus by Kuch and Mebs (2007). And similar scenario for that northern Bungarus species B. suzhenae and B. multicinctus which have narrower body bands. The difference between hemipenial morphology of B. candidus (RH06153) and B. wanghaotingi (both typical and Southern Indochina populations) further confirmed the identification of RH06153 when sequence data was unavailable.

Based on comprehensive morphological comparisons of specimens and molecular evidence, we identified additional morphological characters that can be used to be help identify these taxa (e.g., dental morphology, the patterns on head, ventral body and tail, and large spines on hemipenis). We note that the number of maxillary teeth is taxonomically significant in identifying species of Bungarus and might indicate divergences in feeding and/or defense behavior. $B$. suzhenae sp. nov. only possesses three posterior maxilla teeth, a character state shared by B. fasciatus and Ophiophagus hannah. However, all members of the $B$. candidus/multicinctus/wanghaotingi complex possess four posterior maxilla teeth, a character state that is likely a synapomorphy in comparison to B. suzhenae sp. nov. (Fig. 8).

The species of the $B$. candidus/multicinctus/wanghaotingi complex show feeble genetic divergences (Suppl. material 1: Table S3), with the uncorrected pairwise distances of cyt $b$ between $B$. candidus, B. multicinctus and $B$. wanghaotingi ranging from 1.6\%-3.3\%. These distances are lower than those between other Bungarus species (ranging from $9.7 \%$ to $28.6 \%$ ). However, morphological comparisons showed clear differences between these closely related species. According to Kuch (2007), B. candidus, B. multicinctus and B. wanghaotingi diverged between Middle to Late Pleistocene (> 0.8-1.5 MYA). During the Pleistocene, southeast Asia and southern China went through very frequent sea level oscillations (Voris 2000; Inger and Voris 2001) and the $B$. candidus/multicinctus/wanghaotingi complex may have experienced several hybridization events, introgression or incomplete lineage sorting. We encourage future studies to examine the $B$. candidus/multicinctus/wanghaotingi complex using genomic data, ecological niche modelling and broader sampling, which would help to better understand the evolutionary history of these medically important snakes.

For easier identification, an updated Key to Kraits based on Slowinski (1994) was compiled (note that the identification of this key is still experimental, confirmation by comparing more characters or by sequencing is strongly recommended):

la More than 13 dorsal scale rows 2

lb 13 dorsal scale rows

Bungarus flaviceps

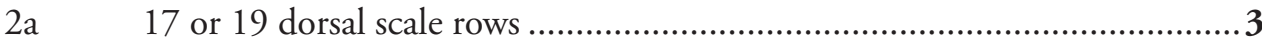

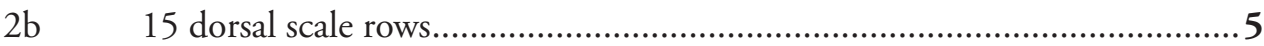

3a Loreal plate present ..................................................................... persicus

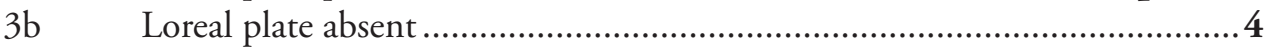


4a White bands on body B. sindanus

$4 \mathrm{~b} \quad$ White spots on body B. walli

Subcaudals divided .6

Subcaudals single 7

6a Inversely V-shaped light on dorsal head B. slowinskii $6 b$ Without inversely $\mathrm{V}$-shaped light on dorsal head B. bungaroides

\section{$7 \mathrm{a}$}

Vertebral row of dorsal scales enlarged anteriorly. 8

$7 \mathrm{~b} \quad$ Vertebral row of dorsal scales not enlarged anteriorly ... B. lividus Bands or rings on body

$8 \mathrm{~b} \quad$ No bands or rings on body .................................................... . niger

9a Light bands or rings white ........................................................ 10

9b Light bands yellow .......................................................... B. fasciatus

10a Rings on body ............................................................ B. ceylonicus

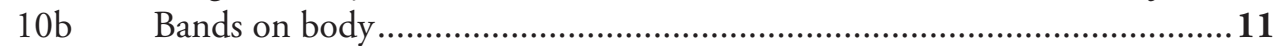

11a More than 20 white bands .......................................................... 12

$11 \mathrm{~b} \quad 11-14$ white bands ................................................... magnimaculatus

12a More than 26 white bands ............................................................ 13

12b Less than 26 white bands ............... B. candidus, or wide white crossbanded $B$. wanghaotingi from Southern Indochina and Peninsular Malaysia

13a At least some white bands occurring in pairs......................... B. caeruleus

$13 \mathrm{~b} \quad$ White bands not in pairs................................................................ 14

$14 \mathrm{a}$ White bands equidistant from each other along body ...... B. andamanensis

14b White bands closer to each other posteriorly than anteriorly....................15

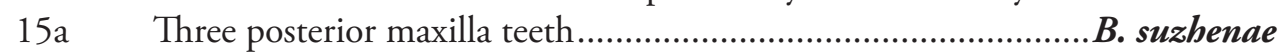

15b Four posterior maxilla teeth ........................................................... 16

16a Ventral surface of tail immaculate white or with dots, large spines on hemipenes mostly pointy.

B. wang-

haotingi (typical populations from Northern Indochina and China)

16b Ventral surface of tail with broad dark bands or patches, large spines on hemipenes papilla-like in shape and blunt

B. multicinctus

\section{Acknowledgements}

We wish to thank Robert Jadin, Patrick David, Lee Grismer for their helpful comments and suggestions on our manuscript. We thank Justin L. Lee for his English revision and helpful suggestions. We thank Ralf Hendrix for sharing photos of hemipenes of $B$. candidus. We thank Peng Guo and Zhang Liang for providing partial samples. We are grateful for help from Yong-Sheng Zhang and Qiang-Bang Gong of Tongbiguan Nature Reserve. We thank Yi-Wu Zhu for sharing a specimen. This study is supported by Biodiversity Investigation, Observation and Assessment Program of Ministry of Ecology and Environment of China (2019-2023) and the Natural Science Foundation of Jiangsu Province, China (BK20160103), the Second Tibetan Plateau Scientific Expedition and Research Program (STEP, Grant 
No. 2019QZKK05010503 and No. 2019QZKK0705) and the Strategic Priority Research Program of the Chinese Academy of Sciences (Grant No. XDA23080101) to Jian-Ping Jiang.

\section{References}

Abtin E, Nilson G, Mobaraki A, Hosseini AA, Dehgannejhad M (2014) A new species of krait, Bungarus (Reptilia, Elapidae, Bungarinae) and the first record of that genus in Iran. Russian Journal of Herpetology 21: 243-250.

Ahsan M, Rahman M (2017) Status, distribution and threats of kraits (Squamata: Elapidae: Bungarus) in Bangladesh. Journal of Threatened Taxa 9: 9903-9910. https://doi. org/10.11609/jott.2929.9.3.9903-9910

Arevalo E, Davis SK, Sites Jr JW (1994) Mitochondrial DNA sequence divergence and phylogenetic relationships among eight chromosome races of the Sceloporus grammicus complex (Phrynosomatidae) in central Mexico. Systematic Biology 43: 387-418. https://doi. org/10.1093/sysbio/43.3.387

Baig KJ, Masroor R, Arshad M (2008) Biodiversity and ecology of the herpetofauna of Cholistan Desert, Pakistan. Russian Journal of Herpetology 15: 193-205.

Barlow A, Pook CE, Harrison RA Wüster W (2009) Co-evolution of diet and prey-specific venom activity supports the role of selection in snake venom evolution. Proceedings of the Royal Society B 276: 2443-2449. https://doi.org/10.1098/rspb.2009.0048

Biswas S, Sanyal DP (1978) A new species of krait of the genus Bungarus Daudin, 1803 (Serpentes: Elapidae) from the Andaman Island. The journal of the Bombay Natural History Society $75(1): 179-183$.

Blyth E (1860) Report of curator, Zoological Department. Journal and Proceedings of the Asiatic Society of Bengal 29: 87-100.

Boulenger GA (1890) The Fauna of British India, Including Ceylon and Burma. Reptilia and Batrachia. Taylor \& Francis, London, 365-372. https://www.biodiversitylibrary.org/page/4388100

Boulenger GA (1896) Catalogue of the snakes in the British Museum (Vol. 3). Taylor \& Francis: London, 727 pp.

Burbrink FT, Lawson R, Slowinski JB (2000) Mitochondrial DNA phylogeography of the polytypic North American rat snake (Elaphe obsoleta): a critique of the subspecies concept. Evolution 54: 2107-2118. https://doi.org/10.1111/j.0014-3820.2000.tb01253.x

Casewell NR, Wagstaff SC, Wüster W, Cook DAN, Bolton FMS, King SI, Pla D, Sanz L, Calvete JJ, Harrison RA (2014) Medically important differences in snake venom composition are dictated by distinct postgenomic mechanisms. Proceedings of the National Academy of Sciences of the USA 111: 9205-9210. https://doi.org/10.1073/pnas.1405484111

Casewell NR, Wüster W, Vonk FJ, Harrison RA, Fry BG (2013) Complex cocktails: the evolutionary novelty of venoms. Trends in Ecology and Evolution 28: 219-229. https://doi. org/10.1016/j.tree.2012.10.020

Chang LS, Lin SK, Huang HB, Hsiao M (1999) Genetic organization of $\alpha$-bungarotoxins from Bungarus multicinctus (Taiwan banded krait): evidence showing that the production 
of $\alpha$-bungarotoxin isotoxins is not derived from edited mRNAs. Nucleic acids research 27(20): 3970-3975. https://doi.org/10.1093/nar/27.20.3970

Che J, Chen HM, Yang JX, Jin JQ, Jiang K, Yuan ZY, Murphy RW, Zhang YP (2012) Universal COI primers for DNA barcoding amphibians. Molecular Ecology Resources 12: 247-258. https://doi.org/10.1111/j.1755-0998.2011.03090.x

Chen YL, Lin YL, Lin TE (2016) Application of Species Identification via Mitochondrial COI DNA Barcoding for Viperidae and Elapidae Species in Taiwan. Taiwan Journal of Biodivers 18(2): 145-156.

Dowling HG (1951) A proposed standard system of counting ventrals in snakes. British Journal of Herpetology 1: 97-99.

Fry BG, Winkel KD, Wickramaratna JC, Hodgson WC, Wüster W (2003) Effectiveness of snake antivenom: species and regional venom variation and its clinical impact. Journal of Toxicology - Toxin Reviews 22: 23-34. https://doi.org/10.1081/TXR-120019018

Hillis DM, Bull JJ (1993) An empirical test of bootstrapping as a method for assessing confidence in phylogenetic analysis. Systematic biology 42(2): 182-192. https://doi. org/10.1093/sysbio/42.2.182

Hoang DT, Chernomor O, von Haeseler A, Minh BQ, Le SV (2017) UFBoot2: Improving the ultrafast bootstrap approximation. Moloecular Biology and Evolution 35: 518-522. https://doi.org/10.1093/molbev/msx281

Hou Y, Cui X, Canul-Ku M, Jin S, Hasimoto-Beltran R, Guo Q, Zhu M (2020) ADMorph: A 3d digital microfossil morphology dataset for deep learning. IEEE Access 8: 148744 148756. https://doi.org/10.1109/ACCESS.2020.3016267

Huelsenbeck JP, Ronquist F, Nielsen R, Bollback JP (2001) Bayesian inference of phylogeny and its impact on evolutionary biology. Science 294: 2310-2314. https://doi.org/10.1126/ science. 1065889

Inger RF, Voris HK (2001) The biogeographical relations of the frogs and snakes of Sundaland. Journal of Biogeography 28: 863-891. https://doi.org/10.1046/j.1365-2699.2001.00580.x

Jiang K (2010) A method for evaginating the hemipenis of Preserved snakes. Sichuan Journal of Zoology 29(1): 122-123. [In Chinese]

Jiang Y, Li Y, Lee W, Xu X, Zhang Y, Zhao R, Zhang Y, Wang W (2011) Venom gland transcriptomes of two elapid snakes (Bungarus multicinctus and Naja atra) and evolution of toxin genes. BMC genomics 12(1): 1-13. https://doi.org/10.1186/1471-2164-12-1

Khan MS (2002) A Guide to the Snakes of Pakistan. Frankfurt Contributions to Natural History (Vol. 16). Edition Chimaira, Frankfurt am Main.

Kharin VE, Orlov NL, Aranjeva NB (2011) New records and redescription of rare and littleknown elapid snake Bungarus slowinskii (Serpentes: Elapidae: Bungaridae). Russian Journal of Herpetology 18(4): 284-294.

Kuch U, Kizirian D, Truong NQ, Lawson R, Donnelly MA, Mebs D, Lannoo MJ (2005) A New Species of Krait (Squamata: Elapidae) from the Red River System of Northern Vietnam. Copeia 2005: 818-833. https://doi.org/10.1643/0045-8511(2005)005[0818:ANSOKS]2.0.CO;2

Kuch U, Mebs D (2007) The identity of the Javan Krait, Bungarus javanicus Kopstein, 1932 (Squamata: Elapidae): evidence from mitochondrial and nuclear DNA sequence analyses and morphology. Zootaxa 1426: 1-26. https://doi.org/10.11646/zootaxa.1426.1.1 
Kuch U (2007) The Effect of Cenozoic Global Change on the Evolution of a Clade of Asian Front-fanged Venomous Snakes: (Squamata: Elapidae: Bungarus). PhD thesis, Frankfurt am Main, Johann Wolfgang Goethe-Universität.

Kumar S, Stecher G, Tamura K (2016) MEGA7: molecular evolutionary genetics analysis version 7.0 for bigger datasets. Molecular biology and evolution 33: 1870-1874. https://doi. org $/ 10.1093 / \mathrm{molbev} / \mathrm{msw} 054$

Lanfear R, Calcott B, Ho SY, Guindon S (2012) Partition Finder: combined selection of partitioning schemes and substitution models for phylogenetic analyses. Molecular Biology and Evolution 29: 1695-1701. https://doi.org/10.1093/molbev/mss020

Leviton AE, Gibbs Jr RH, Heal E, Dawson CE (1985) Standards in herpetology and ichthyology: Part I. Standard symbolic codes for institutional resource collections in herpetology and ichthyology. Copeia 1985: 802-832.

Leviton AE, Wogan GO, Koo MS, Zug GR, Lucas RS, Vindum JV (2003) The Dangerously Venomous Snakes of Myanmar Illustrated Checklist with Keys. Proceedings of The California Academy of Sciences 54: 22-27.

Leviton AE, Zug GR, Vindum JV, Wogan GO (2008) Handbook to the dangerously venomous snakes of Myanmar. California Academy of Sciences, San Francisco.

Liu LF, Chang CC, Kuo KW, Liau MY (1998) Genetic characterization of the mRNAs encoding $\alpha$-bungarotoxin: Isoforms and RNA editing in Bungarus multicinctus gland cells. Nucleic acids research 26(24): 5624-5629. https://doi.org/10.1093/nar/26.24.5624

Mebs D, Narita K, Iwanaga S, Samejima Y, Lee CY (1971) Amino acid sequence of $\alpha$-bungarotoxin from the venom of Bungarus multicinctus. Biochemical and biophysical research communications 44(3): 711-716. https://doi.org/10.1016/S0006-291X(71)80141-9

Mell R (“1929” (1931)) List of Chinese snakes. Lingnan science journal, Canton 8: 199-219.

Nguyen SV, Ho CT, Nguyen TQ (2009) Herpetofauna of Vietnam. Chimaira, Frankfurt, 768 pp. Nguyen L-T, Schmidt HA, von Haeseler A, Minh BQ (2015) IQ-TREE: a fast and effective stochastic algorithm for estimating maximum-likelihood phylogenies. Molecular biology and evolution 32: 268-274. https://doi.org/10.1093/molbev/msu300

Nguyen SN, Nguyen VDH, Nguyen TQ, Le NTT, Nguyen LT, Vo BD, Vindum JV, Murphy RW, Che J, Zhang YP (2017) A new color pattern of the Bungarus candidus complex (Squamata: Elapidae) from Vietnam based on morphological and molecular data. Zootaxa 4268: 563-572. https://doi.org/10.11646/zootaxa.4268.4.7

Nirthanan S, Charpantier E, Gopalakrishnakone P, Gwee MC, Khoo HE, Cheah LS, Bertrand D, Kini RM (2002) Candoxin, a novel toxin from Bungarus candidus, is a reversible antagonist of muscle $(\alpha \beta \gamma \delta)$ but a poorly reversible antagonist of neuronal $\alpha 7$ nicotinic acetylcholine receptors. Journal of Biological Chemistry 277(20): 17811-17820. https:// doi.org/10.1074/jbc.M111152200

Pope CH (1928) Four new snakes and a new lizard from South China. American Museum novitates 325: 1-4.

Pope CH (1935) The reptiles of China: turtles, crocodilians, snakes, lizards (Vol. 10). In: Reeds CA (Ed.) Natural history of Central Asia. American Museum of Natural History, New York, 335-339.

Rao DQ, Zhao EM (2004) Bungarus bungaroides, A Record New to China (Xizang AR) with a Note on Trimeresurus tibetanus. Sichuan Journal of Zoology 23: 213-214. 
Ronquist F, Teslenko M, Van Der Mark P, Ayres DL, Darling A, Höhna S, Larget B, Liu L, Suchard MA, Huelsenbeck JP (2012) MrBayes 3.2: efficient Bayesian phylogenetic inference and model choice across a large model space. Systematic Biology 61: 539-542. https://doi.org/10.1093/sysbio/sys029

Sivaperuman C, Venkataraman K (2018) Indian Hotspots: Vertebrate Faunal Diversity, Conservation and Management. Springer, 23-35. https://doi.org/10.1007/978-981-10-6983-3_16

Slowinski JB (1994) A Phylogenetic Analysis of Bungarus (Elapidae) Based on Morphological Characters. Journal of Herpetology 28: 440-446. https://doi.org/10.2307/1564956

Smith MA (1943) The Fauna of British India, Ceylon and Burma, Including the Whole of the Indo-Chinese Sub-Region. Reptilia and Amphibia. 3 (Serpentes). Taylor and Francis, London, 387-390.

Smits T, Hauser S (2019) First Record of the Krait Bungarus slowinskii Kuch, Kizirian, Nguyen, Lawson, Donelly and Mebs, 2005 (Squamata: Elapidae) from Thailand. Tropical Natural History 19: 43-50.

Stamatakis A (2014) RAxML version 8: a tool for phylogenetic analysis and post-analysis of large phylogenies. Bioinformatics 30: 1312-1313. https://doi.org/10.1093/bioinformatics/btu033

Tsai IH, Hsu HY, Wang YM (2002) A novel phospholipase A2 from the venom glands of Bungarus candidus: cloning and sequence-comparison. Toxicon 40(9): 1363-1367. https://doi. org/10.1016/S0041-0101(02)00150-2

Uetz P, Freed P, Hošek J [Eds] (2020) The Reptile Database. http://www.reptile-database.org [accessed on 3 November 2020]

Vogel G, David P, Pauwels OS (2004) A review of morphological variation in Trimeresurus popeiorum (Serpentes: Viperidae: Crotalinae), with the description of two new species. Zootaxa 727: 1-63. https://doi.org/10.11646/zootaxa.727.1.1

Voris H (2000) Maps of Pleistocene sea levels in Southeast Asia: shorelines, river systems and time durations. Journal of Biogeography 27: 1153-1167. https://doi.org/10.1046/j.13652699.2000.00489.x

Wall CF (1907) A new krait from Oudh (Bungarus walli). Journal of the Bombay Natural History Society 17: 608-611.

Wall F (1908) A popular treatise of the common Indian snakes. Part VIII. Journal of the Bombay Natural History Society 18: 711-735.

Whitaker R, Captain A (2004) Snakes of India. Draco Books, Chennai, 500 pp.

Williams DJ, Gutiérrez JM, Calvete JJ, Wüster W, Ratanabanangkoon K, Paiva O, Brown NI, Casewell NR, Harrison RA, Rowley PD, O'Shea M, Jensen SD, Winkel KD, Warrell DA (2011) Ending the drought: new strategies for improving the flow of affordable, effective antivenoms in Asia and Africa. Journal of Proteomics 74: 1735-1767. https://doi. org/10.1016/j.jprot.2011.05.027

Xie Y, Wang P, Zhong G, Zhu F, Liu Q, Che J, Shi L, Murphy RW, Guo P (2018) Molecular phylogeny found the distribution of Bungarus candidus in China (Squamata: Elapidae). Zoological Systematics 43: 109-117. https://doi.org/10.11865/zs.201810

Yang DT, Rao DQ (2008) Amphibia and Reptilia of Yunnan. Yunnan Science and Technology Press, Kuming, 343-352. [In Chinese]

Zhao EM (2006) Snakes of China. Anhui Science, Technology Publishing House, Hefei, 669 pp. 
Zhao EM, Huang MH, Zong Y (1998) Fauna Sinica, Reptilia, Squamata. Serpentes (Vol. 3).

Science Press, Beijing, 334-341.

Zhao EM, Yang DT (1997) Amphibians and Reptilies of the Hengduan Mountains Region.

Science Press, Beijing, 290-293.

\section{Appendix I}

Specimens examined for measurements and morphology; localities as originally stated

B. caeruleus. (9 specimens). "Indes Orientalis" MNHN 7688. "Bengale" MNHN 3952, MNHN 7687. "Malabar” MNHN 7687. "Pondicheri” MNHN 7686. "Pakistan occ" MNHN 1962.239, MNHN 1962.236, MNHN 1962.238, MNHN 1962.237. "Birma” MNHN1893-413.

B. ceylonicus. (1 specimens). "Sri Lanka" MNHN 4259 (1872-32).

B. fasciatus. (1 specimens). "Bengkalis, Siak, Indonesia” RMNH 1667.

B. candidus. (20 specimens). "Palembang, Sumatra, Indonesia” RMNH 11416. "Java, Indonesia” NMW 27730:2, NMW 27730:7, NMW 27730:3, NMW 27730:4; NMW 27740:5, NMW 27740:4, NMW 9486:4, NMW 9486:3, NMW 27730:5, NMW 27730:1, NMW 9486:1, NMW 9486:6, NMW 9486:5, NMW 9486:2, NMW 27711:1, NMW 27711:2, NMW 27711:3. “Johor, Malaysia” SYNU R180411. "Quang Binh, Vietnam” RH06153.

B. multicinctus. China: (24 specimens). "Anhui, China" CIB 12209; "Chongqing, China” CIB 12215. "Fujian, China” CIB 12212, CIB 12204, CIB 12203, CIB 12207, CIB 12206, CIB 12205, CIB DL18090209, CIB DL18090210; “Guangdong, China” CIB 12191, CIB 12194; “Guangxi, China” CIB 12192, CIB 93924, CIB 93923, CIB 104228; “Zhejiang, China” CIB 12208; “Jiangxi, China” CIB 12210, CIB 12211; "Hainan, China” CIB 12197, SYNU R180305; “Guizhou, China” CIB 83793; "Hunan, China” CIB 12213, CIB 12214.

B. wanghaotingi. China: (16 specimens). "Guangxi, China” CIB FCDZ20170806, CIB 104227. "Yunnan, China" CIB 12216, CIB 12201, CIB ML20170801, CIB MLMY20170801, CIB JCR36, CIB JCR36-2, CIB DL2019051401, CIB DL20190525, CIB DL2019070301, CIB DL20190522, CIB JCR2019062003, CIB JCR2019062311, CIB JCR2019061703, CIB JCR2019061807.

B. suzhenae sp. nov. China. (4 specimens). "Yingjiang, Yunnan, China" CIB 116088CIB 116091.

Specimens checked hemipenes:

B. multicinctus. "Guangdong, China" CIB 12191. "Shangyou, Jiangxi, China" CIB 12211. "Nanning, Guangxi, China” CIB 104228. "Lishui, Zhejiang, China” CIB DL2019051701.

B. wanghaotingi. China. "Luodian, Guizhou, China" CIB 83793. "Beiliu, Guangxi, China” CIB 104227. "Mengla, Yunnan, China” CIB MLML20170801.

B. suzhenae sp. nov. "Yingjiang, Yunnan, China" CIB 116089.

B. candidus "Phong Nha-Ke Bang National Park Administration, Quang Binh Province, Vietnam" RH06153. 


\section{Supplementary material I}

\section{Tables S1-S4}

Authors: Ze-Ning Chen, Sheng-Chao Shi, Gernot Vogel, Li Ding, Jing-Song Shi

Data type: phylogenetic data

Explanation note: Table S1. DNA sequences used in this study. Table S2. Best evolution models of each partition combination. Table S3. Uncorrected p-distances between Bungarus species based on 1069 base pairs from the mitochondrial genes cyt b. Table S4. Uncorrected p-distances between Bungarus species based on 613 base pairs from the mitochondrial genes COI.

Copyright notice: This dataset is made available under the Open Database License (http://opendatacommons.org/licenses/odbl/1.0/). The Open Database License $(\mathrm{ODbL})$ is a license agreement intended to allow users to freely share, modify, and use this Dataset while maintaining this same freedom for others, provided that the original source and author(s) are credited.

Link: https://doi.org/10.3897/zookeys.1025.62305.suppl1 